\title{
Synergy between middle infrared and millimeter-wave limb sounding of atmospheric temperature and minor constituents
}

\author{
Ugo Cortesi $^{1}$, Samuele Del Bianco ${ }^{1}$, Simone Ceccherini ${ }^{1}$, Marco Gai ${ }^{1}$, Bianca Maria Dinelli ${ }^{2}$, Elisa Castelli $^{2}$, \\ Hermann Oelhaf ${ }^{3}$, Wolfgang Woiwode ${ }^{3}$, Michael Höpfner ${ }^{3}$, and Daniel Gerber ${ }^{4}$ \\ ${ }^{1}$ Istituto di Fisica Applicata "Nello Carrara", IFAC-CNR, Sesto Fiorentino, Italy \\ ${ }^{2}$ Istituto di Scienza dell'Atmosfera e del Clima, ISAC-CNR, Bologna, Italy \\ ${ }^{3}$ Institute of Meteorology and Climate Research, Karlsruhe Institute of Technology, Karlsruhe, Germany \\ ${ }^{4}$ RAL Space, STFC RAL, Harwell Oxford, Chilton, UK \\ Correspondence to: Ugo Cortesi (u.cortesi@ifac.cnr.it)
}

Received: 6 October 2015 - Published in Atmos. Meas. Tech. Discuss.: 10 November 2015

Revised: 26 April 2016 - Accepted: 27 April 2016 - Published: 24 May 2016

\begin{abstract}
Synergistic exploitation of redundant and complementary information from independent observations of the same target remains a major issue in atmospheric remote sounding and increasing attention is devoted to investigate optimized or innovative methods for the combination of two or more measured data sets. This paper focuses on the synergy between middle infrared and millimeterwave limb sounding measurements of atmospheric composition and temperature and reports the results of a study conducted as part of the preparatory activities of the PREMIER (Process Exploration through Measurements of Infrared and millimeter-wave Emitted Radiation) mission candidate to the Core Missions of the European Space Agency (ESA) Earth Explorer 7. The activity was based on data acquired by the MIPAS-STR (Michelson Interferometer for Passive Atmospheric Sounding - STRatospheric aircraft) and MARSCHALS (Millimetre-wave Airborne Receivers for Spectroscopic CHaracterisation in Atmospheric Limb Sounding) instruments on-board the high-altitude research aircraft M-55 Geophysica during the flight of the PremierEx (PREMIER Experiment) campaign on 10 March 2010 from Kiruna, Sweden, for observation of the Arctic upper troposphere and lower stratosphere. The cloud coverage observed along the flight provided representative test cases to evaluate the synergy in three different scenarios: low clouds in the first part, no clouds in the central part and high tropospheric clouds at the end. The calculation of synergistic profiles of four atmospheric targets (i.e., $\mathrm{O}_{3}, \mathrm{HNO}_{3}, \mathrm{H}_{2} \mathrm{O}$ and temperature) was performed using a posteriori combination of in-
\end{abstract}

dividual retrieved profiles, i.e., Level 2 (L2) data rather than simultaneous inversion of observed radiances, i.e., Level 1 (L1) data. An innovative method of data fusion, based on the Measurement Space Solution (MSS) was applied along with the standard approach of inversion of MARSCHALS spectral radiances using MIPAS-STR retrieval products as a priori information (L1 $+\mathrm{L} 2$ method). A quantitative estimate and cross-check of the results of MSS data fusion and $(\mathrm{L} 1+\mathrm{L} 2)$ method was achieved based on a specific set of quantifiers including the total retrieval error, the number of degrees of freedom, the relative information distribution and the synergy factor.

\section{Introduction}

The growing number and increasing capabilities of Earth Observation missions from space provides a huge amount of remotely sensed data about the state of the atmosphere and of the ocean and land surface, such as those obtained by newgeneration hyper- and ultraspectral sounders (Smith et al., 2009) like the Atmospheric Infrared Sounder (AIRS), the Infrared Atmospheric Sounding Interferometer (IASI) and the Cross-track Infrared Sounder (CrIS), or those expected from the joint EU/European Space Agency program Copernicus (Aschbacher et al., 2012). Substantial improvements in the quality of the retrieved geophysical products result from the continuous effort to enhance the accuracy of sensors and models for acquisition and processing of individual mea- 
surements. In parallel, an alternative and highly promising approach to maximize the information extracted from Earth Observation data is offered by the synergistic use of independent and simultaneous measurements of the same variable, as highlighted by Ingmann et al. (2012) with specific reference to the benefit of merging Sentinel 5 data with measurements from various instruments planned for EUMETSAT EPS-SG (European Organisation for the Exploitation of Meteorological Satellites Polar System - Second Generation). Complementary information on atmospheric and surface parameters is associated with observations performed by remote sounders, which operate in different spectral regions, using similar or different observation geometries (i.e., similar or different observing platforms and/or lines of sight) and can be combined to gain a greater insight into the properties of the measured target. Exploitation of potential synergies between two or more data sets from independent soundings can be achieved either by applying a suitable retrieval model involving simultaneous inversion of the observations or by a posteriori combination of the independent retrieval products from individual measurements. Aires et al. (2012) compared the two strategies for data fusion in the case of multiwavelength remote sensing observations, demonstrating the better efficiency of the synergistic inversion scheme, with application to the retrieval of atmospheric profiles from IASI, the Advanced Microwave Sounding Unit-A (AMSU-A) and the Microwave Humidity Sounder (MHS) on MetOp-A. The present paper focuses on the performances of a posteriori data fusion methods with the purpose of identifying possible candidates to adequately replace the simultaneous retrieval, which is a demanding approach to the exploitation of complementary capabilities of two more measurement strategies. The direct comparison of these alternative methods with the simultaneous retrieval is, however, beyond the scope of this paper. Data assimilation systems, extensively used to exploit the information from observations obtained from multiple sources (see, for instance, Lahoz et al., 2010), were not considered in our study, which primarily aimed at testing methods for the combination of measured data without contribution from models filling spatial or temporal gaps of the observation.

One of the first and more extensive uses of the synergy between remote sensing observations with complementary sensitivities relied on the combination of microwave and optical measurements for profiling of temperature and moisture, as well as of other gaseous compounds and particle matter in the atmosphere, in clear and cloudy sky conditions (Staelin et al., 1995). The advantages of the combined use of observations in these spectral ranges, triggering the adoption of the synergistic approach also in operational sounding in the 1970s, arise from the relative strengths and limitations that characterize the capabilities of passive remote sounding in the microwave and in the infrared (McMillin et al., 1987). In case of limb viewing observations, they consist primarily of
- the small linear temperature dependence of microwave emission occurring in the Rayleigh-Jeans region of the Planck curve at typical atmospheric temperatures and stronger nonlinear temperature dependence of the infrared channels, particularly near $4.3 \mu \mathrm{m}$;

- the much shorter wavelength and higher sensitivity of infrared sensors, permitting many more spectral channels to be combined in a small instrument with a very high angular resolution and achieving a greater spatial resolution;

- the ability of microwave to penetrate through nearly all weather conditions, with little or no attenuation by most non-precipitating cloud particles, with a size much smaller than the microwave wavelengths $(3 \mathrm{~mm}$ to $30 \mathrm{~cm}$ ) and absorption and scattering cross sections roughly proportional to $\lambda^{-2}$ and $\lambda^{-4}$, respectively;

- a wide variety of important molecules displaying rovibrational bands with emission lines well suited for detection in the infrared portion of the atmospheric spectrum. In the $1-10 \mu \mathrm{m}$ window region, atmospheric signals are generally higher than in other parts of the spectrum, because the Planck function has a maximum at about $10 \mu \mathrm{m}$ for atmospheric temperatures (about $250 \mathrm{~K})$.

The differences in spectroscopic properties, propagation through clouds and aerosols and surface emission features make the synergistic use of infrared and microwave observations profitable. These differences also exist - even if to a lesser extent due to the reduced gap in wavelength - between the infrared and millimeter- and sub-millimeter wave ( $\mathrm{mm}$ - and sub- $\mathrm{mm}$ wave, $3 \mathrm{~mm}-300 \mu \mathrm{m}$ ) radiation.

In the specific case of limb sounding, the all-weather capabilities of the microwaves are jeopardized in the $\mathrm{mm}$ and sub-mm spectral range by the water vapor absorption that prevents measurements at low altitudes. Useful observations are made, in any case, in the upper troposphere and lower stratosphere (UTLS) region complementary to measurements made in the thermal infrared (TIR). $\mathrm{H}_{2} \mathrm{O}, \mathrm{O}_{3}$, $\mathrm{N}_{2} \mathrm{O}, \mathrm{CO}$ and $\mathrm{HNO}_{3}$ have features in the sub- $\mathrm{mm} / \mathrm{mm}$ wave region, while $\mathrm{CO}_{2}$ and $\mathrm{CH}_{4}$ that have no permanent dipole moment and cannot be observed. The exploitation of the synergy between infrared and millimeter-wave limb sounding measurements is one of the key strengths of the scientific payload proposed by the PREMIER (Process Exploration through Measurements of Infrared and millimeterwave Emitted Radiation) mission for the investigation of the interactions between chemical, radiative and transport processes in the UTLS with climate (ESA, 2012). PREMIER was one of the three candidate Core Missions of ESA Earth Explorer 7, which underwent the Phase-A feasibility study, but was not selected to proceed to Phase $B$ and $C$ at the end of the evaluation process. Nevertheless, the strong scientific 
case and the technical feasibility resulting from PREMIER preparatory studies have laid the basis to aim at a new opportunity for launch such as that offered by the ESA Call for Ideas of Earth Explorer 9.

The proposed PREMIER spaceborne mission was aimed at investigating processes responsible for interactions between atmospheric composition and climate at the critical heights of the UTLS by carrying a scientific payload composed of an imaging limb sounding Fourier transform spectrometer in the middle infrared (IRLS, InfraRed Limb Sounder) and a millimeter-wave (mm-wave) limb sounder (STEAMR, Stratosphere-Troposphere Exchange And climate Monitor Radiometer).

In this perspective, we report on the lesson learned in a dedicated study, focusing on the investigation of the potential synergy between infrared and mm-wave limb measurements acquired by two airborne precursors of the STEAMR and IRLS remote sounders proposed for PREMIER. In Sect. 2, we introduce the general context of field campaigns conducted to test the capabilities of infrared (IR) and mmwave limb sounding observation of the UTLS from highaltitude aircraft, while in Sect. 3 we describe the methods applied for data fusion and the parameters adopted to evaluate and compare the quality of individual and synergetic products. Section 4 provides an overview of the PremierEx scientific flight on 10 March 2010 and Sect. 5 discusses the results of our investigation and testing on MIPAS-STR (Michelson Interferometer for Passive Atmospheric Sounding - STRatospheric aircraft), MARSCHALS (Millimetrewave Airborne Receivers for Spectroscopic CHaracterisation in Atmospheric Limb Sounding) and fused data; in the Conclusions the main outcomes of the study and perspectives for further development are summarized.

\section{Limb sounding of the UTLS during the PremierEx campaign}

As part of the preparatory activities of PREMIER, a series of engineering and scientific flights with the high-altitude research aircraft M-55 Geophysica was conducted at midlatitudes and high latitudes carrying an infrared and a mmwave limb sounder on board, to demonstrate the measurement concepts proposed for the investigation of chemical, dynamical and radiative processes occurring in the UTLS. The scientific payload on-board the M-55 Geophysica aircraft was comprised of the MIPAS-STR (Michelson Interferometer for Passive Atmospheric Sounding - STRatospheric aircraft) middle infrared Fourier Transform spectrometer and by the MARSCHALS (Millimetre-wave Airborne Receivers for Spectroscopic CHaracterisation in Atmospheric Limb Sounding) mm-wave heterodyne spectrometer. Both instruments performed limb sounding observations with side-viewing geometry on the starboard side of the aircraft during the flights of the Test Campaign in
2009 (TC9 campaign, Oberpfaffenhofen, Germany, November 2009) at midlatitudes and of the scientific campaigns in 2010 (PremierEx campaign, Kiruna, Sweden, March 2010) and in 2011 (ESSenCe campaign, Kiruna, Sweden, December 2011) in the Arctic region. An ESA-supported study was conducted with the objectives of Level 2 (in this paper, we will indicate Level 1 and Level 2 as L1 and L2, respectively) processing of MARSCHALS measurements acquired during the PremierEx flights and of investigating the synergy between mm-wave and infrared limb sounding of the UTLS by using MARSCHALS and MIPAS-STR data. The results of the analysis of MARSCHALS data have been reported in previous papers by Cortesi et al. (2012) and Castelli et al. (2013), while Woiwode et al. (2012) reported the outcome of MIPAS-STR observations during the joint RECONCILE (Reconciliation of essential process parameters for an enhanced predictability of Arctic stratospheric ozone loss and its climate interactions) campaign (von Hobe et al., 2013). Here, we discuss the synergistic use of MARSCHALS and MIPAS-STR data by using an innovative approach to the problem of atmospheric data fusion, compare the quality of synergistic and individual retrieval products and present our conclusions on the potential of combined exploitation of the information associated with mm-wave and IR limb observations of the UTLS. The results reported in this paper are based on data acquired during the PremierEx flight on 10 March 2010. A brief description of the MARSCHALS and MIPAS-STR instruments is given in the following subsections.

\subsection{Millimeter-wave measurements}

Limb sounding in the mm-wave spectral region can satisfactorily meet the challenging requirements for the study of the UTLS, which - despite controlling several important processes - is poorly covered by measurements. In the upper troposphere and lower stratosphere, at millimeter wavelengths, problems can be posed by water vapor attenuation, horizontal gradients and cloud properties. Indeed, the rotational spectrum of water vapor causes a large absorption in the far infrared/sub-millimeter spectral region and significant absorption can be present also in the line wings at millimetric frequencies due to the high water vapor concentration that can be experienced in the troposphere. The long optical path of limb sounding makes the detection of weak absorption features possible, but at the same time observes an average of the atmospheric composition along the path. This approximation is quite acceptable in the stratosphere, where a uniform composition is often present in the horizontal direction, but may pose enhanced problems in the troposphere, where strong horizontal gradients may be present. The main signal loss caused by the presence of clouds in the line of sight of the instrument is due to scattering and, as the observed wavelength becomes longer than the size of the scattering particles, this effect is reduced. For this reason, clouds are usually 
Table 1. Frequency coverage and spectral performance of the three MARSCHALS spectral bands.

\begin{tabular}{llll}
\hline & Band B & Band C & Band D \\
\hline First local oscillator $(\mathrm{LO})$ frequency $(\mathrm{GHz})$ & 317.46 & 337.48 & 360.80 \\
Intermediate frequency (IF) band $(\mathrm{GHz})$ & $12.0-23.6$ & $12.0-21.0$ & $12.0-18.6$ \\
Signal band $(\mathrm{GHz})$ & $293.86-305.46$ & $316.48-325.48$ & $342.20-348.80$ \\
Image band $(\mathrm{GHz})$ & $329.45-341.06$ & $349.48-358.48$ & $372.80-379.40$ \\
Spectral bandwidth $(\mathrm{GHz})$ & 11.66 & 9.20 & 6.80 \\
Channel bandwidth $(\mathrm{GHz})$ & 0.2 & 0.2 & 0.2 \\
Number of channels used & 44 & 40 & 32 \\
Receiver noise temperature $\left(T_{\text {sys }}\right)(\mathrm{K})$ & 6200 & 9800 & 8600 \\
Noise-equivalent brightness temperature $(\mathrm{K})$ & 0.88 & 1.31 & 1.28 \\
Main target species & $\mathrm{O}_{3}$ & $\mathrm{H}_{2} \mathrm{O}(325.2 \mathrm{GHz}), \mathrm{O}_{3}$ & $\mathrm{CO}(345.79 \mathrm{GHz}), \mathrm{HNO}_{3}, \mathrm{O}_{3}$ \\
\hline
\end{tabular}

quite transparent for mm-wave radiation, but for measurements acquired in the presence of thick clouds, the residual effects must be quantified and properly accounted for.

\subsubsection{The MARSCHALS instrument}

MARSCHALS is a heterodyne spectrometer for the measurement of high-resolution spectra of the atmospheric emission in the millimeter and sub-millimeter region with limb sounding geometry (Oldfield et al., 2001). MARSCHALS has been built by an European consortium led by RAL (Rutherford and Appleton Laboratories) under an ESA contract.

The main features of the MARSCHALS instrument are summarized in Table 1.

MARSCHALS uses a vertically scanning antenna to observe the limb emission of the atmosphere in three bands centered around 300,320 and $345 \mathrm{GHz}$, labeled band $\mathrm{B}$, band $\mathrm{C}$ and band $\mathrm{D}$, respectively. Incoming radiation is coupled to each of three heterodyne radiometers, where it is downconverted to the range $12-24 \mathrm{GHz}$, amplified and detected using a single channelizer spectrometer. The total spectral bandwidth of the channelizer spectrometer is $12 \mathrm{GHz}$, split up into 60 channels of $0.2 \mathrm{GHz}$ channel bandwidth. The intermediate frequency bandwidth of the receivers is less than $12 \mathrm{GHz}$ to a varying degree. The signal due to aliased radiances is filtered out by a high-performance single sideband filter, which reduces these signals by at least $30 \mathrm{~dB}$. The antenna scan system employs a dedicated inertial measurement unit to improve the control of the pointing direction. The antenna control loop measures the aircraft roll angle with high precision, corrects for it and stabilizes the instrument line of sight. For more details on the instrument characterization see Castelli et al. (2013) and Moyna et al. (2010).

\subsubsection{Inversion of MARSCHALS limb radiances}

MARC (Millimetre-wave Atmospheric Retrieval Code) has been used to perform the PremierEx MARSCHALS data analysis. MARC was developed under an ESA contract for the analysis of the MARSCHALS calibrated measurements. It was designed as a global fit (Carlotti, 1988), multi-target (Dinelli et al., 2004) retrieval and it uses the optimal estimation (OE) approach along with the Levenberg-Marquardt algorithm (Rodgers, 2000). A detailed description of the main features of the code is provided in Carli et al. (2007) and more details on the parametrization of the atmosphere, on the atmospheric line shape, as well as on the spectroscopic models implemented into MARC can be found in Bianchini et al. (2008). A description of its use for the analysis of real data can be found in Dinelli et al. (2009).

MARC retrieved atmospheric profiles and scalar parameters. The vertical retrieved profiles are temperature, $\mathrm{H}_{2} \mathrm{O}, \mathrm{O}_{3}$, $\mathrm{N}_{2} \mathrm{O}, \mathrm{HNO}_{3}, \mathrm{CO}$, as well as a spectroscopic continuum profile to account for the continuum-like contribution of opaque clouds in the observed frequency region.

Some scalar targets have been introduced in order to assess the quality of the instrumental characterization and to reduce the effect of the main instrumental systematic errors. They are retrieved in the form of one value for each analyzed scan and are the pointing bias (a correction term that enables eventual instrumental mispointings to be accounted for), the radiometric gain and offset (used to correct the radiometric calibration) and the frequency shift (retrieved as a frequency offset applied to the instrument line shape) (Castelli et al., 2013). This simple representation is a first-order tuning of the instrumental parameters, which however does not fully remove the uncertainties in the instrument modeling. The residual uncertainties are therefore also estimated and added to the computation of the systematic errors. MARC algorithm also provides the retrieval diagnostics. The diagnostic quantities are the reduced $\chi^{2}$, the gain of information (GI) and the degrees of freedom (DOFs) (Rodgers, 2000). These quantifiers have already been discussed in Castelli et al. (2013), Dinelli et al. (2009), and Carli et al. (2007).

MARC has been designed in order to treat the complete variance covariance matrix (VCM) of the residuals (defined as the difference between the simulated and the actual measurements), involving also off-diagonal elements. The VCM of the residuals is made of two components: the random com- 
ponent and the systematic component. The random component depends on the detector noise and on the calibration procedure (radiometric gain and offset error propagation and sharing of calibration view) and contains also off-diagonal elements. Actually, correlations do not affect all the matrix, e.g., correlations are present among data referred to the same band and geometry, and among different geometries for those channels that share the same calibration view.

The systematic component consists of contributions associated with either known approximations we introduced in the forward model (FM) to reduce the overall computing time (hereafter indicated as bias errors) or uncertainties in nonretrieved FM parameters. Each systematic error source can be represented in terms of the measured spectral radiances as an error spectrum. The systematic errors are described in Table 2.

The use of the VCM of the systematic errors has two important advantages. Firstly, it improves the retrieval by combining the measurements with a rigorous weighting of the information contained in the different spectral channels. All channels contribute to the retrieval of all parameters, but their contributions are weighted according to their systematic error. Secondly, it directly provides a retrieval error that contains both the random and systematic contributions and, therefore, corresponds to the total error. More details on the mathematics of the MARC retrieval and on the random and systematic errors can be found in Carli et al. (2007) and Dinelli et al. (2007).

\subsection{Infrared observations}

Middle infrared limb sounding allows the observation of temperature and a multitude of trace gas species in the UTLS region with high sensitivity and vertical resolution under cloud-free conditions. Observations at tropospheric tangent altitudes are limited in the presence of opaque clouds and increasing density, width and saturation of trace gas signatures. Observations of MIPAS aboard Envisat (Fischer et al., 2008, and references therein) were utilized to study the chemical composition from tropospheric to mesospheric altitudes. Airborne observations by MIPAS-STR (e.g., Piesch et al., 1996; Woiwode et al., 2012, and references therein) and CRISTANF (e.g., Ungermann et al., 2012) showed that middle infrared observations allow the resolution of narrow vertical structures in trace gas distributions along flight track with high accuracy under cloud-free conditions. The next generation of infrared limb sounders involves imaging detectors, and the airborne prototype instrument GLORIA (Gimballed Limb Observer for Radiance Imaging of the Atmosphere) successfully demonstrated the capabilities of this new detection technique (Friedl-Vallon et al., 2014; Riese et al., 2014). Here, we use observations by the airborne MIPAS-STR to investigate the synergy with the MARSCHALS mm-wave observations under scenarios characterized by different cloudiness.

\subsubsection{The MIPAS-STR instrument}

MIPAS-STR is a cryogenic middle infrared limb sounder and employs four spectral channels in the spectral range from 725 to $2100 \mathrm{~cm}^{-1}$. MIPAS-STR is described in more detail in Piesch et al. (1996); Keim et al. (2008); Woiwode et al. (2012) and Woiwode et al. (2015). The unapodized spectral sampling of MIPAS-STR is $0.036 \mathrm{~cm}^{-1}$. After application of the Norton-Beer Strong apodization, an effective spectral resolution of $0.069 \mathrm{~cm}^{-1}$ (full width at half maximum) is achieved. For the discussed retrievals, selected microwindows in channel 1 (725 to $990 \mathrm{~cm}^{-1}$, were utilized). The noise-equivalent spectral radiance of channel 1 is $\sim 10 \times$ $10^{-9} \mathrm{~W} \mathrm{~cm}^{-2} \mathrm{sr}^{-1} \mathrm{~cm}$. MIPAS-STR includes its own GPSsupported inertial navigation system (Attitude and Heading Reference System, AHRS), and the scan mirror is controlled via a fast control loop. The total pointing accuracy is estimated to be within 0.8 arcmin $(1 \sigma)$ and includes uncertainties of the attitude information from the AHRS, the accuracy of the scan-mirror control and uncertainties of the line of sight retrieval to correct systematic uncertainties. This corresponds to about $100 \mathrm{~m}$ at the lowest tangent altitude of $\sim 5 \mathrm{~km}$ (for details see Woiwode et al., 2012).

\subsubsection{Inversion of MIPAS-STR limb radiances}

For the MIPAS-STR retrieval, the same approach and a similar setup as described in Woiwode et al. (2012) was applied. The microwindows used for the retrievals were (i) 810.5 to $812.9 \mathrm{~cm}^{-1}$ and 956.0 to $958.2 \mathrm{~cm}^{-1}$ for temperature (via $\mathrm{CO}_{2}$ signatures), (ii) 866.0 to $870.0 \mathrm{~cm}^{-1}$ for $\mathrm{HNO}_{3}$, (iii) 781.0 to $781.7 \mathrm{~cm}^{-1}$ and 787.0 to $787.6 \mathrm{~cm}^{-1}$ for $\mathrm{O}_{3}$ and (iv) 795.7 to $796.1 \mathrm{~cm}^{-1}$ for $\mathrm{H}_{2} \mathrm{O}$. Microwindows were selected for low spectral interference with other species and sufficient radiance while avoiding saturation of spectral features. Initial guess profiles for pressure and temperature were taken from the European Centre for Medium-Range Weather Forecasts (ECMWF) via NILU (Norwegian Institute for Air Research). The same temperature profiles were used as a priori profiles for the temperature retrieval. Initial guess and a priori profiles for the trace gases' volume mixing ratio (VMR) were taken from the polar winter profiles for MIPAS V3.1 of Remedios et al. (2007), with the $\mathrm{CO}_{2}$ profile updated for the Arctic winter 2009/10. Forward calculations were performed using KOPRA (Karlsruhe Optimized and Precise Radiative transfer Algorithm) (Stiller et al., 2002) and inversion was performed utilizing KOPRAFIT (Höpfner et al., 2001). The profiles of the target parameters were retrieved utilizing Gauss-Newton iterations subjected to first-order TikhonovPhillips regularization (Phillips, 1962; Tikhonov, 1963). In case of low information included in the measurements, the applied constraint forces the retrieved profile towards the shape of the a priori profile, but not to the absolute values. The strength of the constraint is adjusted via the regularization parameter. More details about the applied inversion 
Table 2. MARSCHALS systematic errors: bias and parameter errors.

\begin{tabular}{|c|c|}
\hline Bias errors calculated by differencing FM calculations (without/with) approximation & Main effects (in Kelvin) \\
\hline Missing molecules in MARSCHALS spectroscopic database compared to HITRAN 2004 & $\mathrm{H}_{2} \mathrm{~S}(0.0015)$ and $\mathrm{NO}(0.0014)$ \\
\hline Use of a reduced number of lines of the spectroscopic database & Of the order of a few hundredths of $\mathrm{K}$ \\
\hline Use of irregular frequency grid in the cross section computation & Less than 0.2 \\
\hline Parameter errors calculated by differencing FM calculations (perturbed/unperturbed) & Main effects (in Kelvin) \\
\hline Uncertainties in spectroscopic parameters & $\begin{array}{l}\mathrm{O}_{2}, \mathrm{O}_{3} \text { and } \mathrm{HNO}_{3} \text { (less than 1.5), } \\
\mathrm{H}_{2} \mathrm{O}(1.2), \mathrm{N}_{2} \mathrm{O}(1)\end{array}$ \\
\hline Uncertainties in profiles of interfering species & $\mathrm{CH}_{3} \mathrm{Cl}(7)$ by $\mathrm{OCS}(1)$ \\
\hline Uncertainties in high-altitude column of target species & 3.9 associated with $\mathrm{O}_{3}$ \\
\hline Uncertainty in radiometric gain, estimated & of the order of 2.4 \\
\hline Uncertainty in channel response characterization & less than 0.4 \\
\hline Uncertainty in antenna response characterization & less than 1 \\
\hline Uncertainty in sideband response characterization & of the order of 2 \\
\hline
\end{tabular}

approach are found in Höpfner et al. (2001). The retrieval was performed sequentially: after the retrieval of a systematic line of sight correction, temperature was retrieved, followed by the subsequent retrievals of $\mathrm{HNO}_{3}, \mathrm{O}_{3}$ and $\mathrm{H}_{2} \mathrm{O}$. The error budget for the retrieved parameters includes the spectral noise error (from noise covariance matrix), the 0.8 arcmin line of sight error and $2 \%$ radiometric gain error. For temperature, furthermore, the uncertainty resulting from a $5 \%$ error in the $\mathrm{CO}_{2}$ mixing ratios was considered as an estimate to account for both errors in the spectral line data and the $\mathrm{CO}_{2}$ profile applied. In case of the trace gas retrievals, uncertainties in the retrieved VMRs resulting from the uncertainties of the previously retrieved temperature profiles were considered. Except the noise error and the spectroscopic error, the resulting errors were estimated by performing additional retrievals with the discussed parameters modified by the indicated values and by calculating the differences in the retrieved profiles. In the retrievals of $\mathrm{HNO}_{3}, \mathrm{O}_{3}$ and $\mathrm{H}_{2} \mathrm{O}$, spectroscopic errors of 8,7 and $10 \%$ were taken into account, respectively, and a linear propagation of these errors into the retrieved profiles was assumed. The respective uncertainties of the individual retrieval results were treated as $1 \sigma$ errors and were combined by the root of the square sum to the total error. In case of the trace gas retrievals, the total error is dominated by the adopted spectroscopic uncertainties. While especially the line of sight error and radiometric gain error are expected to be variable, all errors except the spectral noise error are termed as systematic errors in this context (see above).

\section{Infrared and millimeter-wave data synergy: methodology and performance evaluation}

We investigated the potential of data fusion from limb measurements of the UTLS with remote sounders operating in the mm-wave and middle infrared region, by performing a comparative evaluation of two methodologies for combination of independent sets of observations, here indicated as the Measurement Space Solution (MSS) method and the $(\mathrm{L} 1+\mathrm{L} 2)$ method. In this section, we report a brief description of the selected methods and of the parameters adopted for estimating the quality of the individual retrieval products and of the fused results.

\subsection{MSS data fusion method}

In our study, we combined the information associated with MIPAS-STR measurements in the infrared and to MARSCHALS measurements in the mm-wave region, by applying the Measurement Space Solution method developed by Ceccherini et al. (2009) and already successfully applied to IASI and MIPAS-ENVISAT data fusion for the retrieval of ozone total column (Ceccherini et al., 2010a) and vertical profile (Ceccherini et al., 2010b). The MSS approach to data fusion is an innovative tool in the category of methods for a posteriori combination of individual retrieval products from independent measurements. Here, we recall the principles of this approach and the interested reader can find the details and the equations in Ceccherini et al. (2010b) and references therein.

The MSS method provides the retrieved profile as the sum of a component belonging to the measurement space (the space generated by the rows of the Jacobian matrix of the FM) and a component belonging to the null space (the orthogonal complement space to the measurement space). The MSS is the component of the profile in the measurement space and is represented using an orthonormal basis of the measurement space; therefore, the uncertainties associated with the components of the profile in this basis are uncorrelated with each other. The MSS includes all the information from the observations without any a priori information. On the other hand, the observations do not contain any information on the component of the profile belonging to the 
null space, which can only be estimated by the use of some a priori information or other external constraints. The MSS method has the advantage that the vertical grid on which the retrieved profile is represented can be chosen as fine as desirable without relying on any a priori information and thus removing the need for any interpolation for subsequent steps of data processing. Furthermore, the unmeasured component that requires the use of some a priori information is kept separate and does not need to be used in subsequent operations. When different independent measurements of the same profile are available, we can calculate the MSSs of these measurements on the same vertical grid so that all the measurement spaces are subspaces of the same complete space. The fusion of these measurements is obtained by calculating the MSS in the sum space of the individual measurement spaces (that is the space including all vectors that are the sum of vectors of the individual measurement spaces). This new MSS (the MSS of the data fusion) includes all the information contained in the observations of the measurements to be fused without any bias due to a priori information. In order to represent the data fusion product, it is necessary to represent the vertical profile in a complete space (not in a subspace as the one in which the MSS is represented) and the choice of a suitable constraint providing the null space component is required. In Ceccherini et al. (2009) the vertical profile was obtained by selecting the smoothest profile compatible with the observations. In Ceccherini et al. (2010b) the vertical profile was obtained by performing a weighted mean between the MSS and an a priori profile, the weights being the inverses of the covariance matrices.

In this paper, for the first time we use the representation of the vertical profile that is obtained using the TikhonovPhillips regularization for the purpose of data fusion. The approach is similar to that reported in Ceccherini et al. (2010b); that is, the profile is given by the formula of the weighted mean, but the inverse of the a priori covariance matrix is substituted by the regularization matrix. Therefore, the vertical profile is given by

$\boldsymbol{x}=\left(\mathbf{S}_{\mathrm{MSS}}^{-1}+\mathbf{R}\right)^{-1}\left(\mathbf{S}_{\mathrm{MSS}}^{-1} \boldsymbol{x}_{\mathrm{MSS}}+\mathbf{R} \boldsymbol{x}_{\mathrm{a}}\right)$,

where $\boldsymbol{x}_{\text {MSS }}$ is the profile obtained by the MSS, $\mathbf{S}_{\text {MSS }}$ is its covariance matrix whose inverse is calculated as specified below, $\boldsymbol{x}_{\mathrm{a}}$ is an a priori profile and $\mathbf{R}$ is the regularization matrix.

The profile $\boldsymbol{x}_{\mathrm{MSS}}$ is given by

$\boldsymbol{x}_{\mathrm{MSS}}=\mathbf{V} \boldsymbol{a}$,

where $\boldsymbol{a}$ is the vector including the MSS components and $\mathbf{V}$ is the matrix whose columns represent the basis of the measurement space. From a physical point of view, this basis, as pointed out at the beginning of this section, is chosen so that the projections of the profile on it, i.e., the elements of $\boldsymbol{a}$, have errors that are uncorrelated with each other. Since we want to represent $\boldsymbol{x}_{\text {MSS }}$ in the complete space, we complete the matrix $\mathbf{V}$ with columns that represent a basis of the null space. The components of $\boldsymbol{a}$ related to the null space are put to zero, but as we will see, these values are not influential. Since the covariance matrix of $\boldsymbol{a}$ is equal to $\boldsymbol{\Lambda}^{-2}$ (Ceccherini et al., 2010b), where $\boldsymbol{\Lambda}$ is the diagonal matrix containing the singular values of the matrix $\mathbf{S}_{y}^{-\frac{1}{2}} \mathbf{K}\left(\mathbf{S}_{y}\right.$ being the covariance matrix of the observations and $\mathbf{K}$ the Jacobian matrix of the FM), then we can write the inverse of the covariance matrix of $\boldsymbol{x}_{\mathrm{MSS}}$ as

$\mathbf{S}_{\mathrm{MSS}}^{-1}=\mathbf{V} \boldsymbol{\Lambda}^{2} \mathbf{V}^{T}$.

Since the components in the null space correspond to singular values equal to zero in the matrix $\boldsymbol{\Lambda}$, Eq. (3) associates infinity value to the errors of the components in the null space. As a consequence, the values of these components will be determined by the regularization whatever value we have put in the vector $\boldsymbol{a}$ for these components. In contrast to the previous applications of the MSS to data fusion (Ceccherini et al., 2010a, b) in the analysis reported in this paper the systematic errors are taken into account and included in the $\mathbf{S}_{y}$ matrix. Each systematic error component has been added to the $\mathbf{S}_{y}$ matrix, as shown in Eq. (4):

$\mathbf{S}_{y}=\mathbf{S}_{y, \text { random }}+\sum_{i=1, N} \boldsymbol{\epsilon}_{i} \boldsymbol{\epsilon}_{i}^{\mathrm{T}}$,

where $\boldsymbol{\epsilon}_{i}$ are the error spectra (Carli et al., 2007) and $N$ are the number of the systematic effects considered.

The regularization matrix is given by

$\mathbf{R}=\gamma \mathbf{L}_{1}^{\mathrm{T}} \mathbf{L}_{1}$

where $\mathbf{L}_{1}$ is the matrix representing the first derivative operator and $\gamma$ is a parameter with which we tune the regularization strength. The covariance matrix and the averaging kernel (AK) matrix of the profile can be obtained by Eq. (1):

$\mathbf{S}=\left(\mathbf{S}_{\mathrm{MSS}}^{-1}+\mathbf{R}\right)^{-1} \mathbf{S}_{\mathrm{MSS}}^{-1}\left(\mathbf{S}_{\mathrm{MSS}}^{-1}+\mathbf{R}\right)^{-1}$

$\mathbf{A}=\left(\mathbf{S}_{\mathrm{MSS}}^{-1}+\mathbf{R}\right)^{-1} \mathbf{S}_{\mathrm{MSS}}^{-1}$.

For the calculation of the AK matrix we have taken into account that $\boldsymbol{x}_{\text {MSS }}$ is the unregularized solution and, therefore, its AK matrix is the identity matrix.

\section{$3.2(\mathrm{~L} 1+\mathrm{L} 2)$ method}

In this work, we adopted the MSS data fusion methodology as the primary tool to combine information from independent data sources, in order to prove the effectiveness of an innovative approach to data fusion and to highlight its unique advantages compared to other a posteriori combination algorithms, such as the $(\mathrm{L} 1+\mathrm{L} 2)$ method. The $(\mathrm{L} 1+\mathrm{L} 2)$ method 
for synergistic analysis of mm-waves and infrared measurements consists in the inversion of MARSCHALS L1 data using OE with MIPAS-STR L2 products (analyzed using the Tikhonov-Phillips regularization technique) adopted as a priori information. As a priori information, we define the L2 profile obtained from MIPAS-STR data analysis and the associated VCM containing both the random and systematic error contributions.

\subsection{Quantifiers of the individual and synergistic data products quality}

The comparison between individual and synergistic retrieval products was conducted by relying on a selection of quality quantifiers. These included a comprehensive set of parameters for the estimate of the performance of individual and synergistic retrieval products, as well as an additional quantity to evaluate the efficiency of the synergistic effects.

We briefly report the definition and scope of the adopted quantifiers.

\section{- Total retrieval error}

The total uncertainty on individual and synergistic retrieval products is defined, both for the MSS (Measurement Space Solution) and (L1 + L2) analysis. It includes the random and systematic components. The error due to spatial and temporal mismatch of collocated limb measurements is assumed to be negligible for each selected pair of MIPAS-STR and MARSCHALS sequences.

The total retrieval error obtained by the MSS method is the square root of the diagonal elements of the VCM defined in Eq. (6). In this work, the same external constraint (Tikhonov-Phillips regularization) is added to the MSS of MARSCHALS measurements, to the MSS of MIPAS-STR measurements and to fused MSS data. We remind the reader here that the retrieval errors also take the systematic effects into account; for this reason, we can define the total retrieval error. Please note that this approach of representing the total error is different from the a posteriori combination of systematic and random uncertainties used for the initial MIPAS-STR data product (see Sect. 2.2.2).

In the (L1 + L2) analysis, we define the total retrieval error for MIPAS-STR as the quadratic combination of the retrieval error and of the systematic errors added a posteriori. The MARSCHALS initial data products (i.e., the retrieved profiles obtained by using the inverse processing scheme described in Sect. 2.1.2) and (L1 + L2) data products include the systematic errors in the VCM of the observations; therefore, the retrieval procedure directly provides the total retrieval error (Carli et al., 2007).

- Degrees of freedom

We define and calculate the number of DOFs for the in- dividual and combined retrieval as the trace of the corresponding AK matrices.

The number of DOFs can be used to evaluate the effect of Tikhonov-Phillips regularization and the OE method on the respective retrievals.

In the case of MARSCHALS, as a consequence of the use of OE, the lower limit for the DOFs is 0 , while in the case of the Tikhonov-Phillips method applied for MIPAS-STR, at least one DOF is always left (independent from the regularization strength), since the absolute position of a profile is completely determined by the measured data.

Moreover, it has to be noted that in the MSS (Measurement Space Solution) analysis, the AK matrices used to calculate the DOFs are defined in all cases with respect to a common a priori information; in the presented (L1 + L2) analysis, on the contrary, the DOFs of individual and synergistic retrievals depend on different a priori information and external constraints (TikhonovPhillips regularization and $\mathrm{OE}$ ) and cannot share a common reference.

\section{- Relative information distribution}

The relative information distribution (RID) is a quality quantifier for indirect measurements, derived from the diagonal of the Fisher Information Matrix (Fisher, 1935), which provides an absolute assessment (not relying on any a priori information) as a function of altitude of the information that the observations contain on the retrieved profile. This quantifier has been introduced in Ceccherini et al. (2012) and successfully used to evaluate the quality of the operational products of the MIPAS instrument (Ceccherini et al., 2013). Following Ceccherini et al. (2012), we recall the definition of RID.

The Fisher information matrix $\mathbf{F}$ associated with the inverse problem of indirect measurements of vertical atmospheric profiles is given by

$\mathbf{F}=\mathbf{K}^{\mathrm{T}} \mathbf{S}_{y}^{-1} \mathbf{K}$,

where $\mathbf{K}$ is the Jacobian matrix of the FM calculated in the minimum of the cost function minimized by the retrieval and $\mathbf{S}_{y}$ is the covariance matrix of the observations. The trace of the Fisher information matrix is referred to as the measurement quality quantifier (MQQ). If we indicate with $F_{i i}$ the diagonal elements of the matrix $\mathbf{F}$, the MQQ is the sum of the quantities $F_{i i}$ (called MQQ components), which provide the contributions to the total MQQ of the measurement of the vertical profile at the different altitudes. Since the MQQ component $F_{i i}$ is proportional to the square of the altitude interval $\Delta z_{i}$ associated with the $i$ th level of the profile, it is useful to define the information distribution as equal to

$f_{i}=\frac{F_{i i}}{\Delta z_{i}^{2}}$, 
which is independent of the retrieval grid. The MQQ components $F_{i i}$ represent absolute quality quantifiers that do not take into account the magnitude of the retrieved profile. It is useful to introduce the relative MQQ components that are dimensionless quantities given by the products of $F_{i i}$ with the square of the retrieved parameters $x_{i}$. Similarly the RID (relative information distribution) is defined as equal to

$f_{i} x_{i}^{2}=\frac{F_{i i} x_{i}^{2}}{\Delta z_{i}^{2}}$

We have decided to use the RID as a quantifier of the information provided by the measurements as alternative to the Shannon information gain often used, given by

$G I=\frac{1}{2} \log _{2}\left(\frac{\left|\mathbf{S}_{\mathrm{a}}\right|}{|\mathbf{S}|}\right)$,

where $\left|\mathbf{S}_{\mathrm{a}}\right|$ is the determinant of an a priori covariance matrix and $|\mathbf{S}|$ is the determinant of the retrieved profile. This choice is due to the following reasons. The use of the Shannon information gain is rigorous when the retrieval is performed using the OE method, and it determines the information gain with respect to the a priori profile used in the retrieval. However, this quantifier is not applicable to retrievals performed using the Tikhonov-Phillips regularization, as in the case of MIPAS-STR measurements. Indeed, in this case there is not an a priori covariance matrix that can be used in Eq. (11). Furthermore, while the Shannon information gain is a single value characterizing the overall information gain, the RID (relative information distribution) is a vertical profile describing the information provided by the observations as a function of altitude. Therefore, the RID, different from the Shannon information gain, is able to discriminate at which altitudes the observations have provided information. This feature of the RID is particularly useful to assess the performance of the data fusion process, because it allows the detailed evaluation of the complementarities and the redundancies of the measurements that are fused.

- Synergy factor

An additional parameter can be introduced to quantify the synergy of two sets of independent measurements. According to the definition given by Aires (2011) and implemented in Aires et al. (2012), the synergy factor (SF) of a retrieval scheme using $\mathrm{N}$ sources of information $\left(x_{1}, x_{2}, \ldots, x_{N}\right)$ is the ratio of the errors of the retrieval using the best single information, $\operatorname{Min}\left(E\left(x_{i}\right)\right)$ $(i=1, \ldots, N)$, with the errors of the retrieval using all the sources of information $E\left(x_{1}, x_{2}, \ldots, x_{N}\right)$. This synergy factor is $>1$ when a synergy between the two individual data sets really exists.

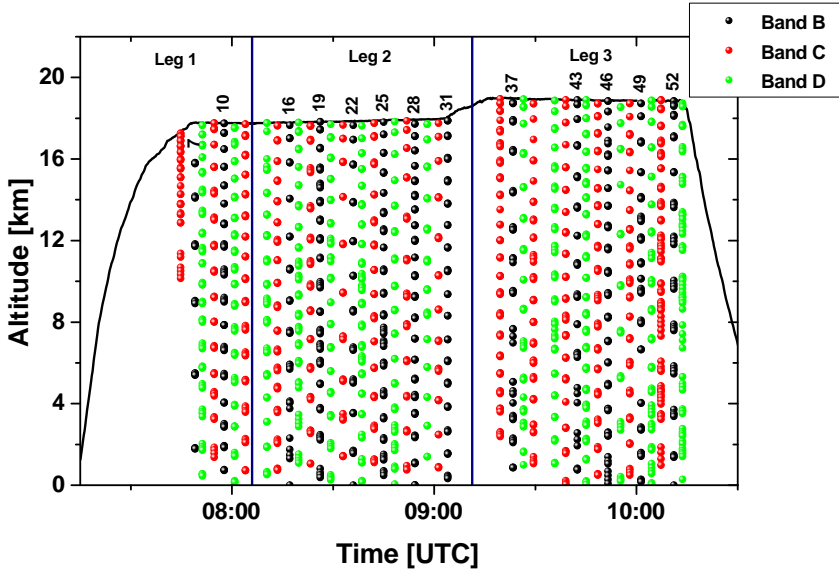

Figure 1. The flight altitude and MARSCHALS tangent points plotted vs. the acquisition time (UTC) for the Arctic Geophysica flight on 10 March 2010.

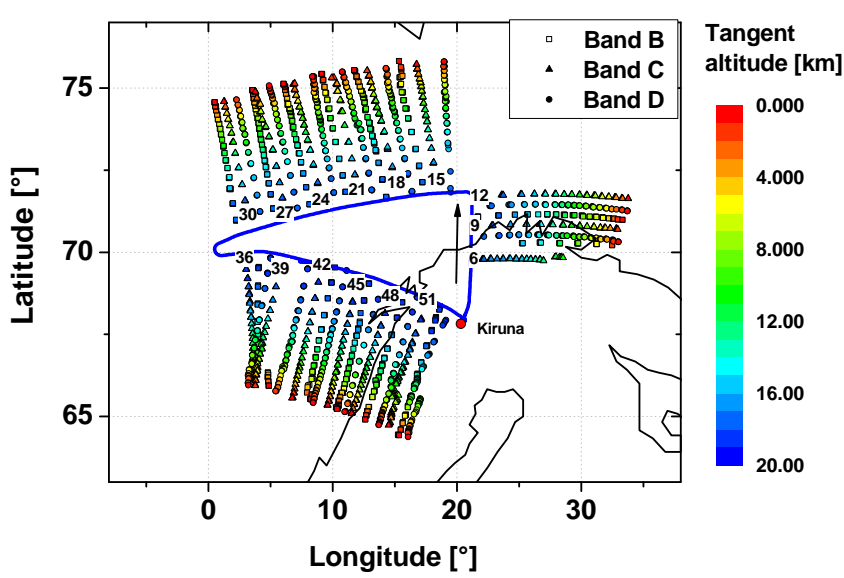

Figure 2. Geolocations of MARSCHALS limb sounding measurements.

\section{The PremierEx flight on 10 March 2010}

The data set used for the investigation of the synergy of mmwave and infrared limb sounding of the Arctic UTLS consists of the measurements acquired by MARSCHALS and by MIPAS-STR during the flight of the PremierEx campaign conducted from Kiruna, Sweden (lat. 67.8 ${ }^{\circ}$, long. $20.4^{\circ} \mathrm{E}$ ), on 10 March 2010. Major details from the point of view of MARSCHALS and MIPAS-STR are provided in Castelli et al. (2013) and Woiwode et al. (2012) (for the RECONCILE flight on 2 March 2010), respectively.

The scientific objective of the flight was to resolve the horizontal mixing processes in the Arctic UTLS and to investigate the synergy between mm-wave and infrared remote sensing observations in the presence of clouds. Actually, in two parts of the flight (MARSCHALS scans 6-31 and scans 35-53 shown in Figs. 1 and 2), both the flight track and the aircraft altitude were suitable for the acquisi- 


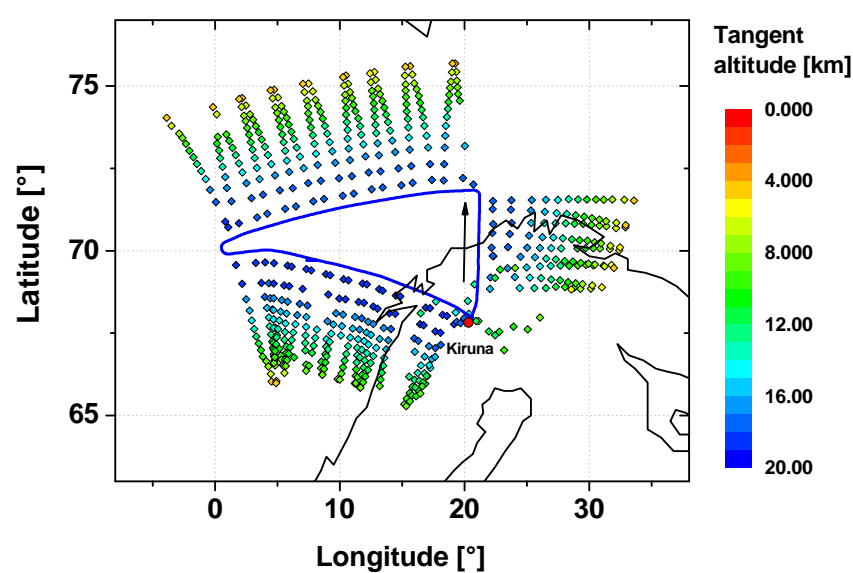

Figure 3. Geolocations of MIPAS-STR limb sounding measurements.

tion of good quality limb scanning measurements, even if the vertical distribution of mm-wave measurements along the scan was not uniform (see Fig. 1). The tangent points of the MARSCHALS observations covered the vertical range from $\sim 0 \mathrm{~km}$ to flight altitude.

The observed atmospheric scenario shows peculiar characteristics that made this flight a proper benchmark for testing the synergy between mm-wave and infrared limb measurements; see also Castelli et al. (2014). The air masses sampled by the limb instruments originated from both the vortex (that was located above Scandinavia on that day) and the midlatitudes. For this reason, the mixing ratio of some constituents changed along the flight, e.g., $\mathrm{HNO}_{3}$ concentration variation in the presence of filament of vortex air, (Castelli et al., 2013). In particular, the water vapor distribution along the flight shows an enhancement below 7$8 \mathrm{~km}$ from MARSCHALS scan 30 onward (also evident in ECMWF data extracted at average scan positions) that could potentially reduce the sensitivity of $\mathrm{mm}$-wave measurements in this part of the flight at those altitudes.

The cloud coverage of the observed atmospheric scenes along flight track was investigated by applying the cloud index (CI) (Spang et al., 2004) to the MIPAS-STR observations (e.g., Woiwode et al., 2012). The approximate cloud coverage along flight track derived from the MIPAS-STR observations was low clouds $(\sim 8 \mathrm{~km})$ in the first part of the flight (here called leg 1 ), only weak cloud signatures up to $\sim 5 \mathrm{~km}$ in the central part (leg 2) and high tropospheric clouds (up to $10-11 \mathrm{~km}$ ) at the end of the flight (see Fig. 4; opaque clouds are indicated by CI values close to 1). The applied MIPAS-STR sampling program (see also Fig. 4) during flight leg 1 and 2 included limb observations with tangent altitudes between $\sim 5 \mathrm{~km}$ and flight altitude and a vertical spacing of $\sim 1 \mathrm{~km}$ (increased spacing below $8 \mathrm{~km}$ ). During the third flight leg, tangent altitudes below $9 \mathrm{~km}$ were excluded to avoid high tropospheric clouds. Additional upward view-

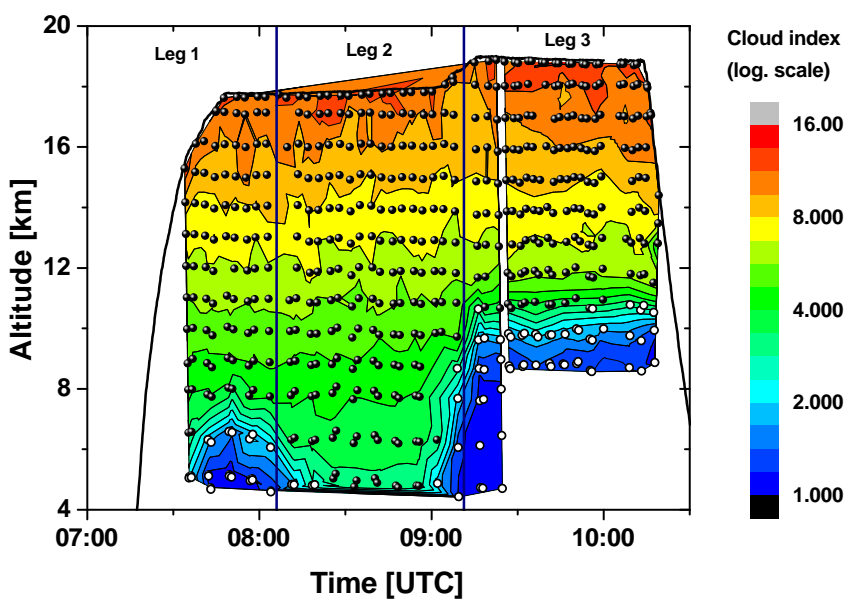

Figure 4. Vertical flight profile of the Geophysica together with tangent points and interpolated CI of the MIPAS-STR observations. White circles indicate MIPAS-STR observations showing CI values lower than the adopted cloud threshold value of 3 (these spectra were omitted in the MIPAS-STR retrievals). CI values close to 1 indicate opaque clouds.

ing observations at 2,5 and $10^{\circ}\left(3\right.$ and $8^{\circ}$ during flight leg 3 ) provided limited information on trace gas distributions above the flight path. In the following, we will show that in several cases the cloud coverage only had a minor impact on the $\mathrm{mm}$-wave measurements and allowed high-quality retrievals of VMR, also in cloudy conditions; thereby, the discussed distribution of the observation scenario provided very significative test cases to evaluate the synergy between infrared and $\mathrm{mm}$-wave observations under scenarios characterized by different cloudiness.

The geographical distribution of MARSCHALS and MIPAS-STR tangent points are shown in Figs. 2 and 3 respectively. A set of best matching limb sequences acquired by MARSCHALS and MIPAS-STR instruments along the flight track was selected, by choosing the MIPAS-STR sequence closest in time for each MARSCHALS sequence. In Table 3, we report the resulting pairs of collocated measurements along with the information about their temporal mismatch. For each scan, MARSCHALS acquired only one spectral band indicated in the second column of Table 3 .

The comparison between individual and synergistic retrieval products was extended to the vertical profiles of the atmospheric targets simultaneously observed by MARSCHALS and by MIPAS-STR, i.e., $\mathrm{O}_{3}, \mathrm{HNO}_{3}$, $\mathrm{H}_{2} \mathrm{O}$ and temperature. 
Table 3. Best matching sequences of MARSCHALS and MIPASSTR measurements selected for the synergistic data analysis.

\begin{tabular}{|c|c|c|c|}
\hline $\begin{array}{r}\text { MARSCHALS } \\
\text { seq. number }\end{array}$ & $\begin{array}{r}\text { MARSCHALS } \\
\text { spectral band }\end{array}$ & $\begin{array}{l}\text { MIPAS-STR } \\
\text { seq. number }\end{array}$ & $\begin{array}{r}\text { Time }(\mathrm{s}) \\
\text { mismatch }\end{array}$ \\
\hline 6 & $\mathrm{C}$ & 01_00734 & -39 \\
\hline 7 & B & 01_00757 & -55 \\
\hline 8 & D & 01_00780 & -71 \\
\hline 9 & $\mathrm{C}$ & 01_00803 & -140 \\
\hline 10 & B & 01_00826 & -121 \\
\hline 11 & D & 01_00826 & 62 \\
\hline 12 & $\mathrm{C}$ & 01_00849 & 19 \\
\hline 14 & D & 01_00895 & 81 \\
\hline 15 & $\mathrm{C}$ & 01_00918 & 40 \\
\hline 16 & B & 01_00941 & 107 \\
\hline 17 & D & 01_00964 & 105 \\
\hline 18 & $\mathrm{C}$ & 01_00987 & 169 \\
\hline 19 & B & 01_00987 & 1 \\
\hline 20 & D & 01_01010 & 34 \\
\hline 21 & $\mathrm{C}$ & 01_01033 & -24 \\
\hline 22 & B & 01_01056 & -5 \\
\hline 23 & D & 01_01079 & -120 \\
\hline 24 & $\mathrm{C}$ & 01_01102 & -68 \\
\hline 25 & B & 01_01125 & -169 \\
\hline 26 & D & 01_01125 & 34 \\
\hline 27 & $\mathrm{C}$ & 01_01148 & 75 \\
\hline 28 & B & 01_01171 & -48 \\
\hline 29 & D & 01_01194 & 8 \\
\hline 30 & $\mathrm{C}$ & 01_01217 & -64 \\
\hline 31 & B & 01_01240 & -79 \\
\hline 36 & $\mathrm{C}$ & 01_01311 & 136 \\
\hline 37 & B & 01_01359 & -88 \\
\hline 38 & D & 01_01381 & -64 \\
\hline 39 & $\mathrm{C}$ & 01_01396 & -2 \\
\hline 41 & D & 01_01426 & 95 \\
\hline 42 & $\mathrm{C}$ & 01_01456 & 5 \\
\hline 43 & B & 01_01471 & 37 \\
\hline 44 & D & 01_01501 & -54 \\
\hline 45 & $\mathrm{C}$ & 01_01516 & 5 \\
\hline 46 & B & 01_01546 & -102 \\
\hline 47 & D & 01_01561 & -45 \\
\hline 48 & $\mathrm{C}$ & 01_01576 & 4 \\
\hline 49 & B & 01_01591 & 48 \\
\hline 50 & D & 02_00020 & -141 \\
\hline 51 & $\mathrm{C}$ & 02_00024 & -76 \\
\hline 52 & B & 02_00039 & -1 \\
\hline 53 & D & 02_00069 & -129 \\
\hline
\end{tabular}

\section{Results and discussion}

In this section, we show the results of individual data processing and of MSS (Measurement Space Solution) data fusion (Sect. 5.1) and discuss the assessment of the synergy by means of the SF (synergy factor) parameter for each of the selected targets (Sect. 5.2) and the comparison of the performance of data fusion using the MSS and the $(\mathrm{L} 1+\mathrm{L} 2)$ approach in the case of $\mathrm{O}_{3}$ (Sect. 5.3).
For a correct interpretation of the plots discussed hereafter, we recall that - as already pointed out in Sect. 2.1.1 - MARSCHALS observation strategy was based on acquisition of single limb scans with sequential spectral coverage in band $\mathrm{B}$, band $\mathrm{C}$ and band $\mathrm{D}$ and with different performance depending on the target species. The periodic patterns observed in MARSCHALS and fused products' vertical cross sections (i.e., in this context, the combined horizontal sequences of retrieved atmospheric parameter profiles) are due to the inclusion of the three bands in the plots.

\subsection{Results of MSS data fusion}

The MSS analysis of the synergy between mm-wave and middle infrared limb sounding was conducted on four atmospheric targets simultaneously observed by MIPAS-STR and by MARSCHALS during the PremierEx flight. The results shown in this section have been obtained by applying the MSS method both to the individual measurements and to calculation of the fused products. For the profile representation, we used the Tikhonov-Phillips regularization parameters (see Eqs. from 1 to 7). The retrieval vertical grid was fixed from 1 to $30 \mathrm{~km}$ in steps of $500 \mathrm{~m}$. The TikhonovPhillips parameter $\gamma$ was equal to $100,6 \times 10^{7}, 200$ and 5 for ozone, nitric acid, water vapor and temperature, respectively. In order to exclude retrieved data strongly affected by the constraint, we only report data points corresponding to diagonal elements of the AK matrix larger than the threshold value of 0.015 in the figures (cf., for instance, Lossow et al., 2011).

For each target, we show the cross sections of the retrieved atmospheric targets versus altitude and sequence number, along with the associated total error and the RID (relative information distribution) and the series of number of DOFs in each leg of the flight and for each set of measurements corresponding to band $\mathrm{B}, \mathrm{C}$ and D of MARSCHALS as a function of MARSCHALS sequence.

\subsubsection{Ozone}

The results obtained for $\mathrm{O}_{3}$ are displayed in Fig. 5. The total retrieval uncertainty on the $\mathrm{O}_{3}$ profiles measured by MARSCHALS is clearly band-dependent, with the best performance obtained for limb sequences acquired by band B. The MIPAS-STR errors increase towards lower altitudes due to the increased value of the combination of the involved error sources. While in leg 2 VMR, error and DOF values are shown down to altitudes of about $5 \mathrm{~km}$; these quantifiers are shown down to only $\sim 8 \mathrm{~km}$ and only about 10 to $11 \mathrm{~km}$ in legs 1 and 3, respectively. In leg 1, this is due to the fact that the observations at lower altitudes had to be excluded from the retrieval due to strong cloud influence (cp. Fig. 4). In leg 3 , on the other hand, the MIPAS-STR sampling program was changed (see Sect. 2.2.1) to avoid high tropospheric clouds expected from the weather forecast. The change in the sam- 

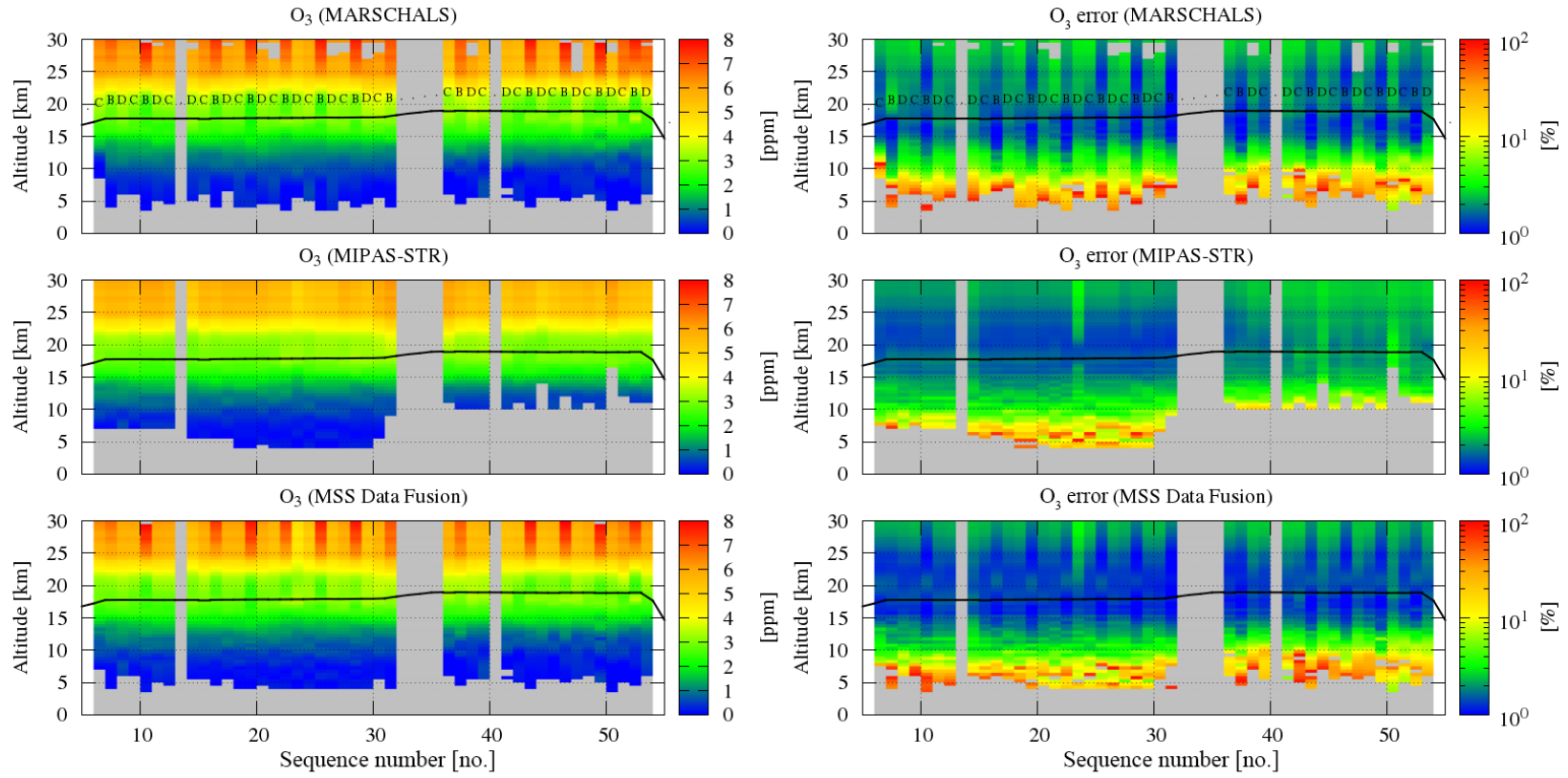

$\mathrm{O}_{3}$ DOF (MARSCHALS Band B)
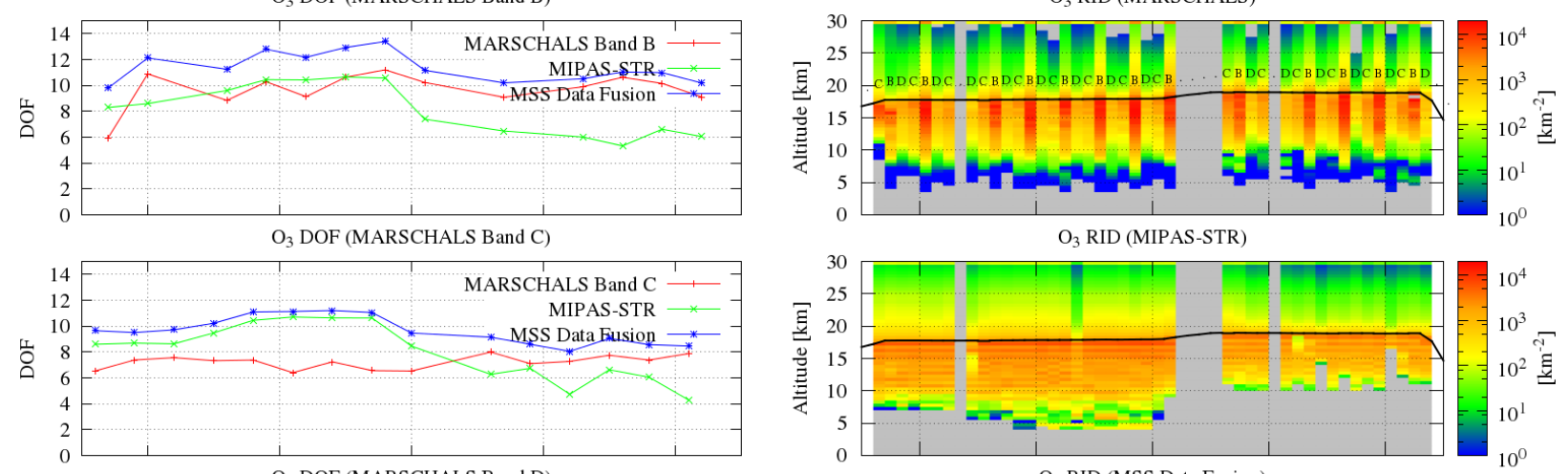

$\mathrm{O}_{3}$ DOF (MARSCHALS Band D)
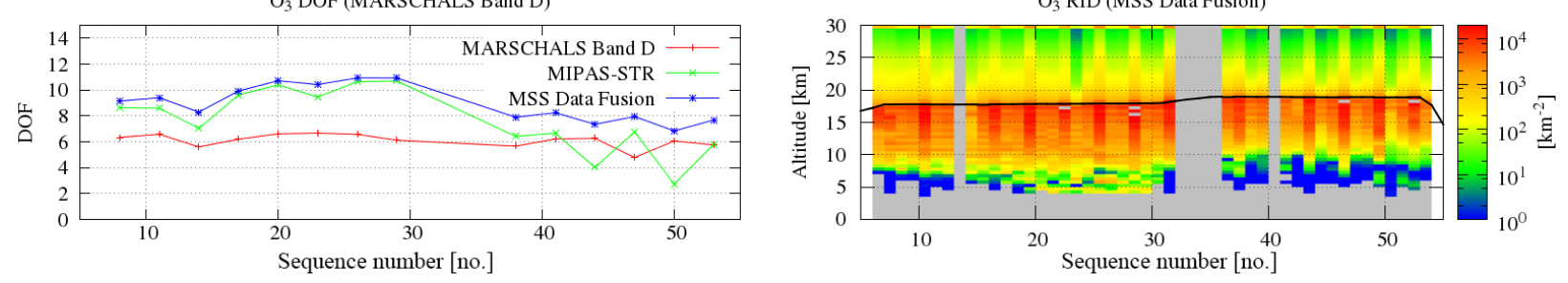

Figure 5. $\mathrm{O}_{3}$ retrieved results obtained from MSS individual analysis and MSS data fusion of MARSCHALS and MIPAS-STR limb sounding observations: vertical profiles (top left panel), total relative error profiles (top right panel), number of DOF (bottom left panel) and RID profiles (bottom right panel). The black line across the maps in this figure, as well as in other figures of this paper, represents the flight altitude. The dotted and bold vertical lines marking the plot of the DOFs, in this figure, as well as in other figures of this paper, identify the border between leg 1 and leg 2 and between leg 2 and leg 3, respectively.

pling program furthermore included a reduction of the upward sampling in order to further enhance horizontal sampling. Together, the limited number of cloud-free observations at tropospheric altitudes and the lower number of upward viewing observations due to the change in the sampling program resulted in slightly enhanced errors at cloud-free altitudes in leg 3 when compared to the other legs. The same applies to the other retrieval targets discussed in the following.

The evidence of the impact of clouds on MIPASSTR measurements, as well of the better performance of MARSCHALS band B with respect to band C and D, can be quantitatively assessed from the analysis of the number of DOFs. For this purpose, we calculated the mean value and the standard deviation of the mean for the number of DOFs 

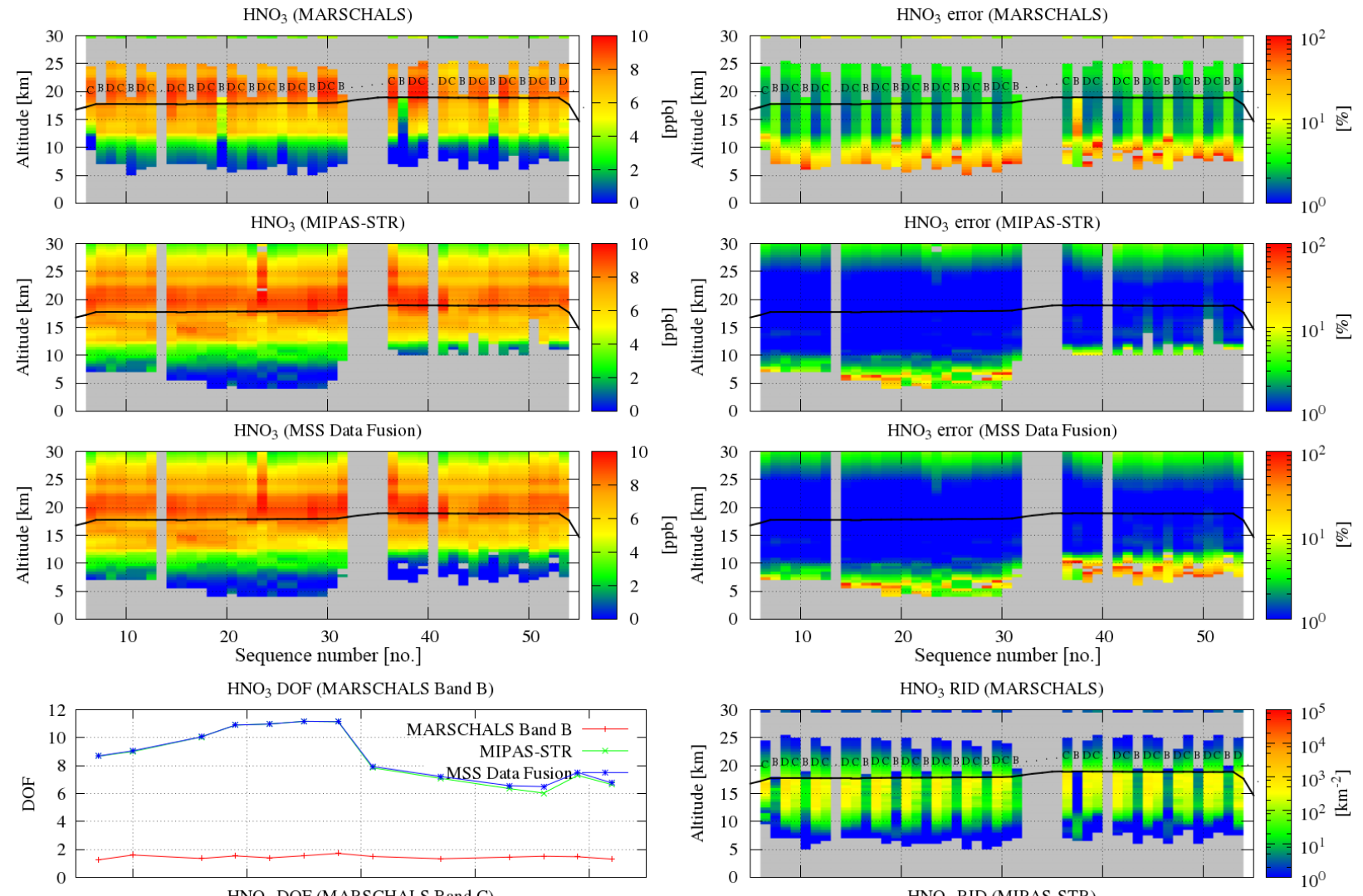

$\mathrm{HNO}_{3} \mathrm{RID}$ (MARSCHALS)
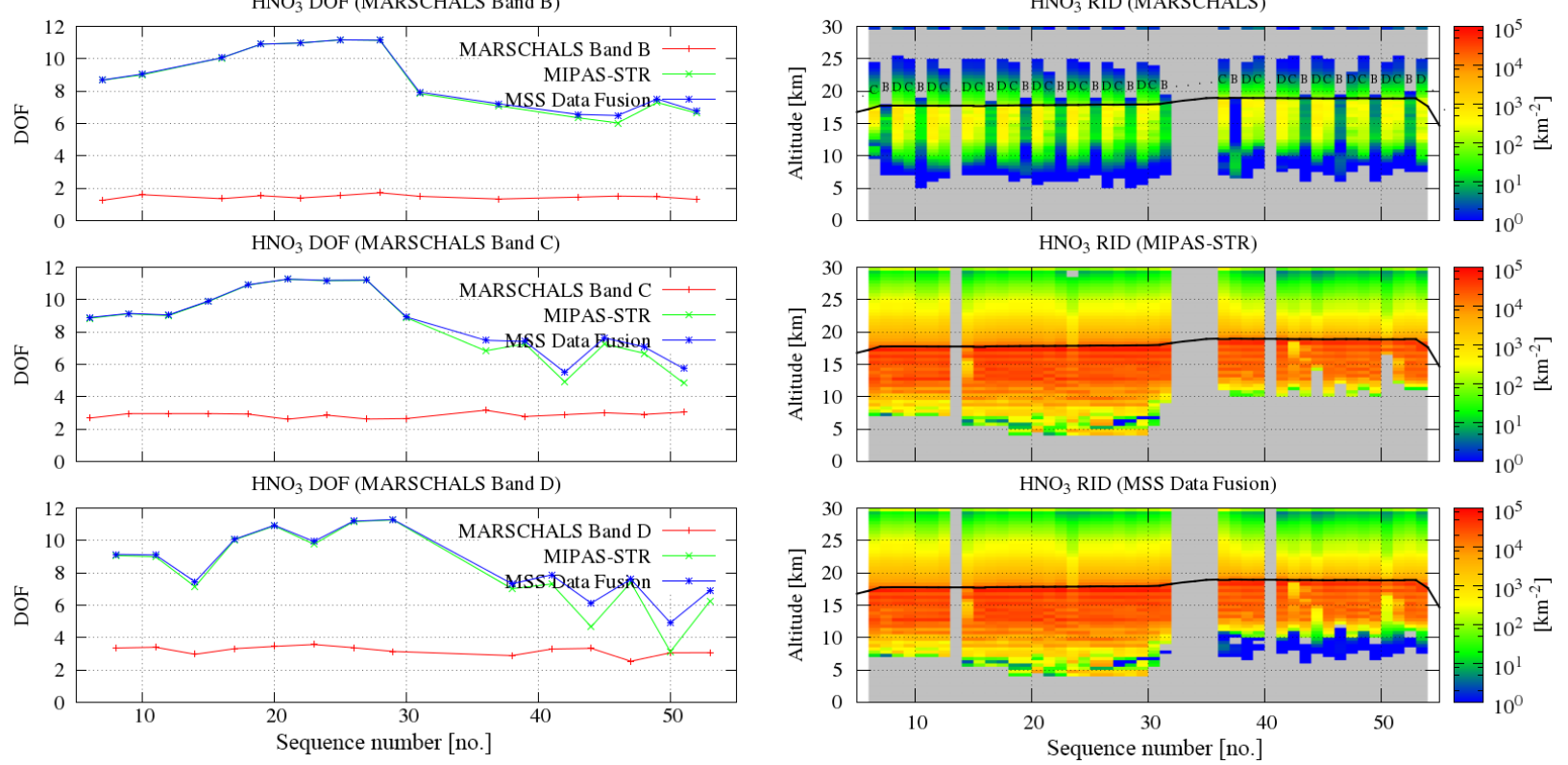

Figure 6. $\mathrm{HNO}_{3}$ retrieved results obtained from MSS individual analysis and MSS data fusion of MARSCHALS and MIPAS-STR limb sounding observations: vertical profiles (top left panel), total relative error profiles (top right panel), number of DOF (bottom left panel) and RID profiles (bottom right panel).

of $\mathrm{O}_{3}$ in each leg and for each band of MARSCHALS. The average number of MIPAS-STR DOFs for ozone is higher in the clear sky conditions of leg 2 (equal to $9.8 \pm 1.1$, if calculated by averaging all MIPAS-STR sequences in leg 2 independently of their coincidence with MARSCHALS acquisitions in different spectral bands), while it decreases to $8.6 \pm 0.1$ in leg 1 and to $5.7 \pm 1.1$ in leg 3 for the occurrence of low-altitude clouds and high-altitude clouds (in spite of the higher flight altitude of leg 3), respectively. For the limb sequences corresponding to acquisitions of MARSCHALS band B, the average number of DOFs of the MSS (Measurement Space Solution) data fusion increases by 2.5 with respect to both MARSCHALS and MIPAS-STR data products in the presence of low clouds (leg 1) and by 2.2 for MARSCHALS and 2.4 for MIPAS-STR in clear sky conditions (leg 2). In leg 3, the difference between the number of DOFs of fused and individual products is much higher for MIPAS-STR (4.5) than for MARSCHALS (0.8), due to the larger impact of high clouds on middle infrared compared to millimeter-wave sounding. 
A similar approach can be applied to the analysis of the RID as defined in Sect. 3.3, showing for each MARSCHALS band a fairly stable vertical profile throughout each of the three legs of the flight, with values systematically higher for band $\mathrm{B}$ than for band $\mathrm{C}$ and D. The RID of the individual measurements confirms that MARSCHALS band B provides the best performance with peak mean values in the three legs of the flight always higher than $\sim 10^{4}$ and located in the altitude range between 15 and $20 \mathrm{~km}$. For band $\mathrm{C}$ and band $\mathrm{D}$, on the contrary, the maximum of the RID profile is reached approximately at the same altitude, but on average never exceeds the threshold of $\sim 4000$. For MIPASSTR observations, the RID profiles averaged on each leg are peaking at about $17-18 \mathrm{~km}$, with values between 5000 and 6000 in low clouds and clear sky conditions, and highlight the reduced capability for $\mathrm{O}_{3}$ sounding below $10 \mathrm{~km}$ in the presence of high-altitude clouds. Lower RID mean values peaking at 3000 to 3500 are found in leg 3 due to the combination of reduced upward sampling and a reduced number of cloud-free observations at lower altitudes. By using the RID (relative information distribution) parameters, it is straightforward to evaluate the benefit of the combination of MARSCHALS and MIPAS-STR measurements, as the MQQ of the fused products is equal to sum of the MQQ of the individual observations.

\subsubsection{Nitric acid}

The results obtained for $\mathrm{HNO}_{3}$ are displayed in Fig. 6 . MIPAS-STR products are generally affected by lower total uncertainties compared to the band-dependent uncertainties of MARSCHALS (with lower errors in band C and D), in particular between 5 and $20 \mathrm{~km}$.

The lower uncertainties of the MIPAS-STR retrieval reflect the error associated with the fused $\mathrm{HNO}_{3}$ data set, which is far better than the MARSCHALS uncertainty. The relatively better capabilities of MIPAS-STR for $\mathrm{HNO}_{3}$ limb sounding are also clearly highlighted in the plots of the DOFs. The number of DOFs for MARSCHALS is quite stable in all phases of the flight; on the contrary, the trend of MIPAS-STR DOFs appears to be closely related to cloudiness. The effect of the MSS fusion on the DOFs, as a consequence, is more pronounced in the third leg of the flight and particularly for MARSCHALS limb scans acquired in band $\mathrm{D}$ and band $\mathrm{C}$, while bit is barely noticeable in band $\mathrm{B}$ due to the low sensitivity of MARSCHALS observations.

Evidence of the better quality of MIPAS-STR measurements of $\mathrm{HNO}_{3}$ vertical distribution emerges from the cross section of the RID parameters from individual observations, especially in the range from 10 to $20 \mathrm{~km}$ and above. MARSCHALS sounding provides a better coverage only at lower altitudes in cloudy conditions, e.g., below the cloud top height $(\mathrm{CTH})$ occurring at about $10 \mathrm{~km}$ in the last section of the flight. The RID values of the $\mathrm{HNO}_{3}$ profiles obtained from the MSS data fusion show the good altitude coverage resulting from the combination of the complementary capabilities of the middle infrared and mm-wave limb sounding.

\subsubsection{Water vapor}

The results obtained for $\mathrm{H}_{2} \mathrm{O}$ are displayed in Fig. 7. Water vapor VMR profiles are best retrieved using data acquired by MARSCHALS band C, as shown by the vertical cross section of the total relative error on MARSCHALS $\mathrm{H}_{2} \mathrm{O}$, where limb sequences with the lowest average uncertainties - i.e., less than $4 \%$ between about 7 and $25 \mathrm{~km}$ along each leg of the flight - are associated with band $\mathrm{C}$ measurements. For band $\mathrm{B}$ and band $\mathrm{D}$, the same threshold value for the total relative error is only achieved in the range between approximately 5 and $10 \mathrm{~km}$. MIPAS-STR total relative error on water vapor is lower than 5-6\%, only around flight altitude.

The analysis of the number of DOFs of the MSS indicates that the combination with MIPAS-STR data set, as expected, introduces substantial differences with respect to the DOFs of MARSCHALS individual measurements in band B and band D. Significant differences are also found when evaluating the number of DOFs of MSS fused results of MIPASSTR and MARSCHALS in band C.

The highest RID values $\left(>10^{3}\right)$ are obtained by MARSCHALS in band C, from $20 \mathrm{~km}$ down to about $10 \mathrm{~km}$. Both MARSCHALS band B and band D RID profiles are above $10^{2}$ only in the limited range of about $5-10 \mathrm{~km}$. MIPAS-STR, however, hardly achieves the threshold value of $10^{3}$ in the whole flight, even if there are considerably higher RID values with respect to MARSCHALS bands B and D at altitudes above $\sim 10 \mathrm{~km}$. As a consequence, the RID values of the MSS fused products show a significant improvement with respect to the values of the individual measurements in the case of observations acquired in MARSCHALS band $\mathrm{B}$ and D, where MIPAS-STR performance results in a RID profile larger than MARSCHALS RID above approximately $10 \mathrm{~km}$.

\subsubsection{Temperature}

The results obtained for temperature are displayed in Fig. 8 . By looking at the estimates of total uncertainties, we can highlight the lower values of the MIPAS-STR error at altitudes above $10 \mathrm{~km}$ throughout the whole flight and the general improvement obtained by MSS data fusion, which makes the increased value of the total error around the height of $10 \mathrm{~km}$ in the presence of high clouds in the final leg of the flight evident.

The number of DOFs for MARSCHALS retrieved profiles of temperature is fairly constant for each band throughout the flight and approximately equal to 5 and 4 in the case of band $\mathrm{B}$ and band $\mathrm{C}$ respectively and between 3 and 4 in the case of band D. The DOF of MIPAS-STR temperature, on the other hand, is on average $8.8 \pm 0.1$ in leg 1 , while it increases to $10.1 \pm 1.1$ in leg 2 and is limited to $6.1 \pm 1.1$ by 

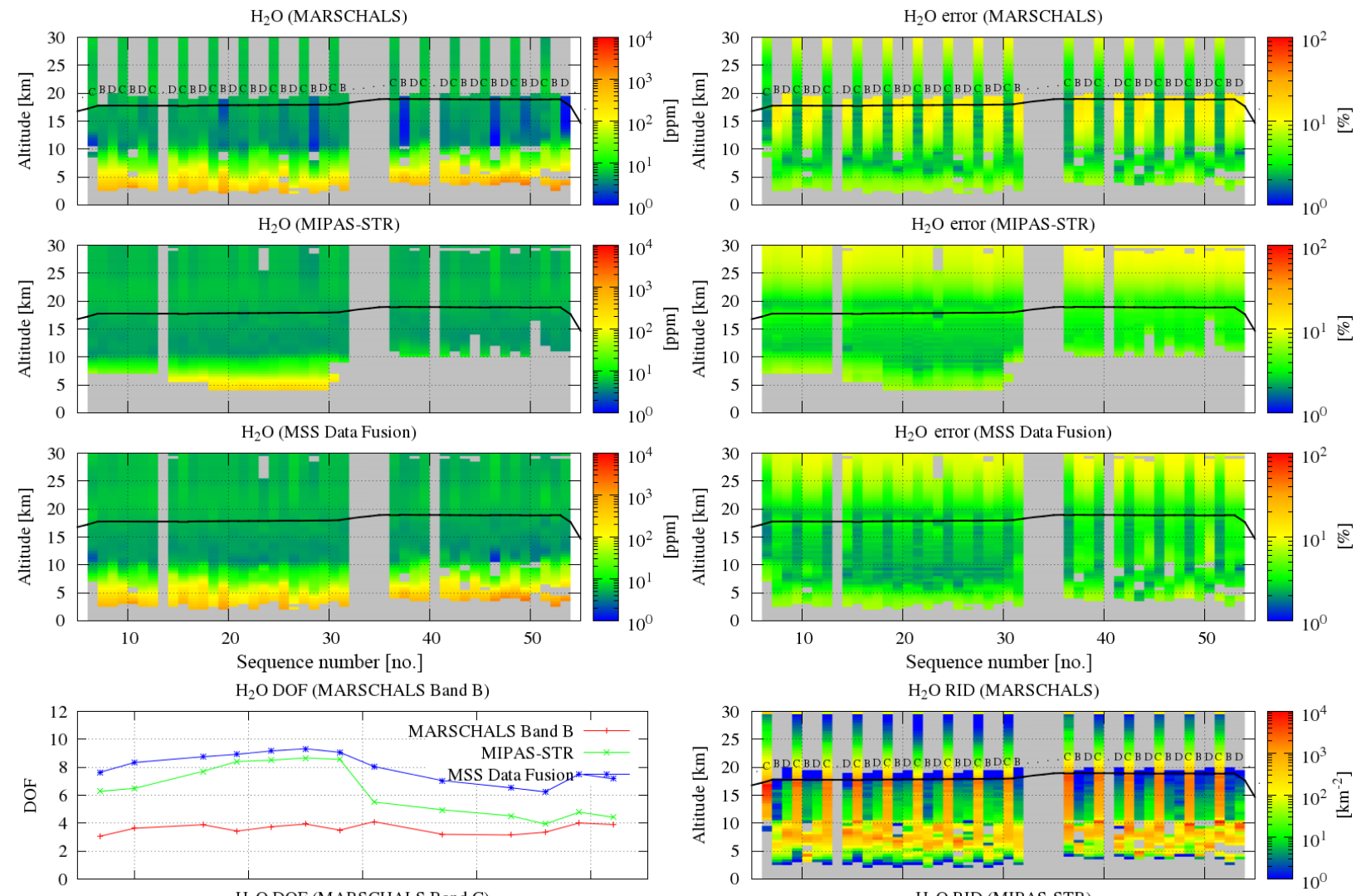

$\mathrm{H}_{2} \mathrm{O}$ RID (MARSCHALS)
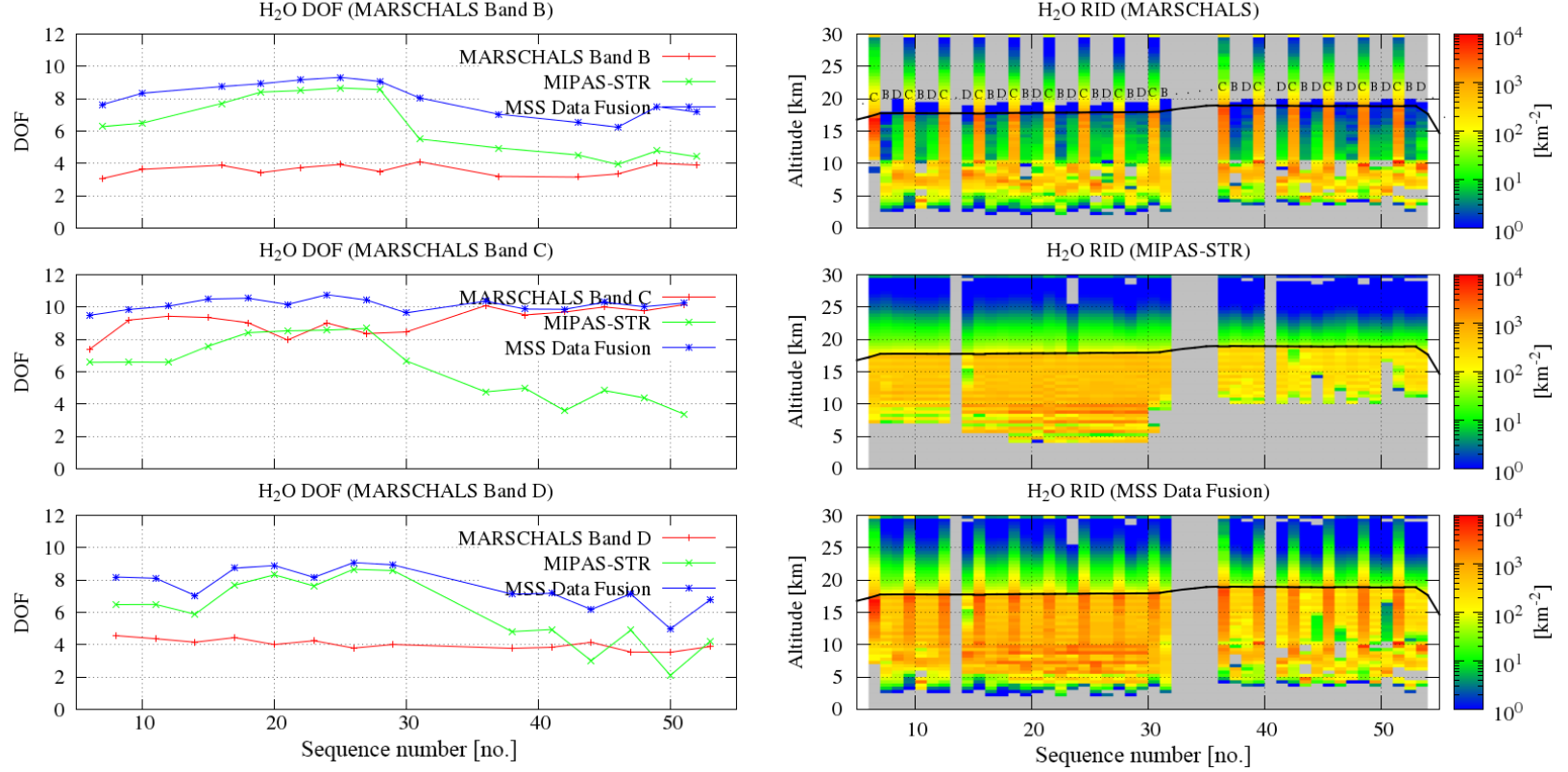

Figure 7. $\mathrm{H}_{2} \mathrm{O}$ retrieved results obtained from MSS individual analysis and MSS data fusion of MARSCHALS and MIPAS-STR limb sounding observations: vertical profiles (top left panel), total relative error profiles (top right panel), number of DOF (bottom left panel) and RID profiles (bottom right panel).

the change in MIPAS-STR sampling program in leg 3 to include only tangent altitudes above $9 \mathrm{~km}$, thus avoiding the forecasted high-altitude clouds.

For temperature, the process of MSS (Measurement Space Solution) data fusion leads to an average increase of the number of DOFs with respect to MIPAS-STR of 1.1 and 1.9 in the presence of clouds (leg 1 and leg 3, respectively) and by 0.8 in the clear sky conditions of leg 2 .

The RID (relative information distribution) of the individual measurements clearly highlights the better performance of MIPAS-STR sounding compared to MARSCHALS, generally showing higher values from flight altitude and above down to the CTH or to the lowest altitude of $5 \mathrm{~km}$ in the clear sky conditions of the second leg. The complementary capabilities of mm-wave measurements with respect to the middle infrared, also for this target, compensate for the lack of sensitivity of MIPAS-STR below $10 \mathrm{~km}$ in the third leg of the flight, with the RID of the fused data demonstrating a homogeneous coverage between $5 \mathrm{~km}$ and flight altitude and 

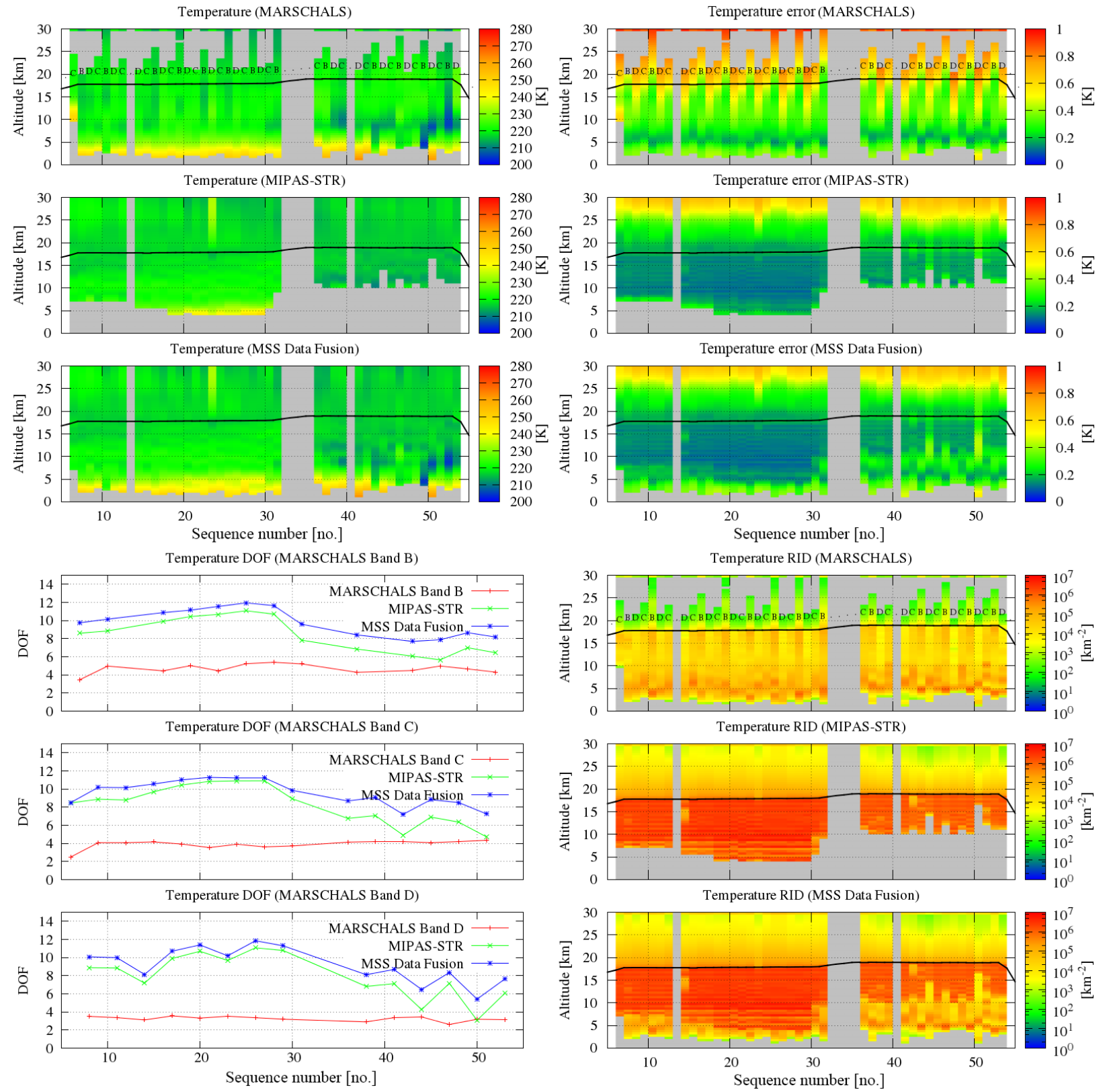

Figure 8. Temperature retrieved results obtained from MSS individual analysis and MSS data fusion of MARSCHALS and MIPAS-STR limb sounding observations: vertical profiles (top left panel), total error profiles (top right panel), number of DOF (bottom left panel) and RID profiles (bottom right panel).

showing slightly lower values due to the presence of clouds both at the beginning and towards the end of the flight.

\subsection{Synergy of MSS data fusion}

In this section, we assess the effect of the synergy between mm-wave and TIR sounding for each of the selected targets. A quantitative estimate of the impact of the synergy on the vertical distribution of each target is obtained by mapping the values of the SF (synergy factor) of the fused data as a function of altitude along the flight track (see Fig. 9).

For $\mathrm{O}_{3}$, we generally observe $\mathrm{SF}$ values strictly larger than 1.0 above the $\mathrm{CTH}$, approximately located at $5 \mathrm{~km}$ and at $10 \mathrm{~km}$ in the first and third leg of the flight, respectively, as indicated by the CI derived from MIPAS-STR limb radiances and reported in Fig. 4. This applies, in particular, to the observations corresponding to MARSCHALS acquisitions in band $\mathrm{C}$ and $\mathrm{D}$, whilst for band $\mathrm{B}$ - with stronger sensitivity to $\mathrm{O}_{3}$ concentration in the mm-wave - the combination 

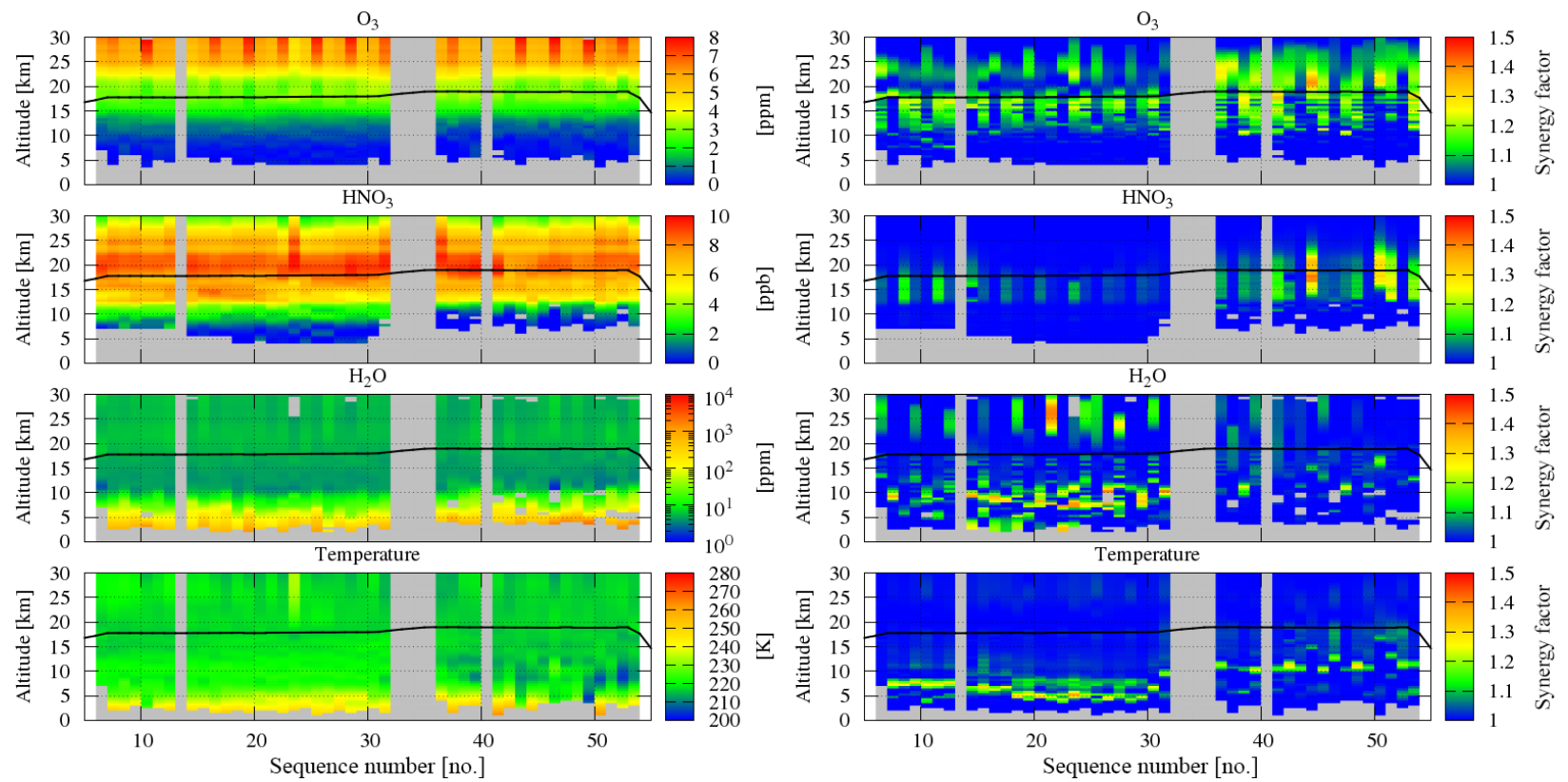

Figure 9. MSS data fusion products (left panel) and SF (right panel) for the atmospheric targets as resulting from MSS individual retrievals and MSS data fusion of MARSCHALS and MIPAS-STR limb sounding observations.

with middle infrared hardly leads to any improvement with respect to the individual measurements below flight altitude.

The $\mathrm{HNO}_{3}$ SF profiles show values between 1.0 and 1.1 in the altitude range between 10 and $25 \mathrm{~km}$, whenever MIPASSTR measurements are combined with MARSCHALS $\mathrm{HNO}_{3}$ profiles retrieved from band $\mathrm{C}$ and band $\mathrm{D}$. The larger impact of data fusion is obtained in the third leg of the flight, in the presence of high-altitude clouds, with mean values of the SF up to 1.2 for measurements acquired in MARSCHALS band D between 10 and $20 \mathrm{~km}$.

The combination of MIPAS-STR and MARSCHALS data generates relatively low synergy with average values of the $\mathrm{H}_{2} \mathrm{O} \mathrm{SF}$ that never exceed the threshold of 1.1, with the only exceptions of the peak found for band B (in the first leg) and band $\mathrm{D}$ (in the second leg) at altitudes between 9 and $10 \mathrm{~km}$ (mean SF up to 1.3) and of values between 1.1. and 1.2 above flight altitude (up to around $25 \mathrm{~km}$ ) for band $\mathrm{C}$.

The effects of synergy on Leg 3 profiles, estimated from the maps of the SF, confirm that the best performances are obtained when combing MIPAS-STR data with MARSCHALS measurements in band B and highlight the fact that the fusion is particularly effective at altitudes between 5 and $10 \mathrm{~km}$ in the presence of low-altitude clouds or in clear sky conditions and around $10 \mathrm{~km}$ in the presence of high clouds. Furthermore, for temperature and even for $\mathrm{H}_{2} \mathrm{O}$, we verified that the information of the MIPAS-STR measurements in the third leg above $10 \mathrm{~km}$ is capable of improving the quality of the fused product, also at the altitudes below $10 \mathrm{~km}$, where only MARSCHALS soundings are available. A similar synergy mechanism was found between MIPAS-
Envisat and IASI-METOP under comparable conditions, as already shown by Ceccherini et al. (2010b)

\subsection{Comparison with the results of $(L 1+L 2)$ method}

We report the results of the $(\mathrm{L} 1+\mathrm{L} 2)$ method compared with the retrieval products from individual measurements in this section. As for the MSS (Measurement Space Solution) data fusion, the ( $\mathrm{L} 1+\mathrm{L} 2)$ method was applied to $\mathrm{O}_{3}, \mathrm{HNO}_{3}$, $\mathrm{H}_{2} \mathrm{O}$ and temperature profiles retrieved from the best matching sequences of MARSCHALS and MIPAS-STR. Here, however,we show the $\mathrm{O}_{3}$ results only (see Fig. 10), because these are representative of the problem associated with this data fusion method.

The total error on $\mathrm{O}_{3}$ VMR values obtained from data fusion is significantly reduced, in the altitude range between 10 and $20 \mathrm{~km}$, compared to total errors of $\mathrm{O}_{3}$ profiles retrieved from MIPAS-STR measurements. In particular, a reduction up to about $60 \%$ is observed in the plots (not shown here) of the total error vertical profile averaged for each band over the three legs of the flight. The number of DOFs of the $(\mathrm{L} 1+\mathrm{L} 2)$ method can be inferior to that of the individual instrument data, because it represents the number of independent parameters that can be retrieved from MARSCHALS measurements in addition to the a priori knowledge given by MIPAS-STR L2 products. The number of DOFs calculated for the MIPAS-STR retrieval of $\mathrm{O}_{3}$ profiles is significantly increased by the combination with MARSCHALS measurements in all spectral bands, with the average DOFs of data fusion equal to 8 in band B, 6 in band $\mathrm{C}$ and 5 in band D. 

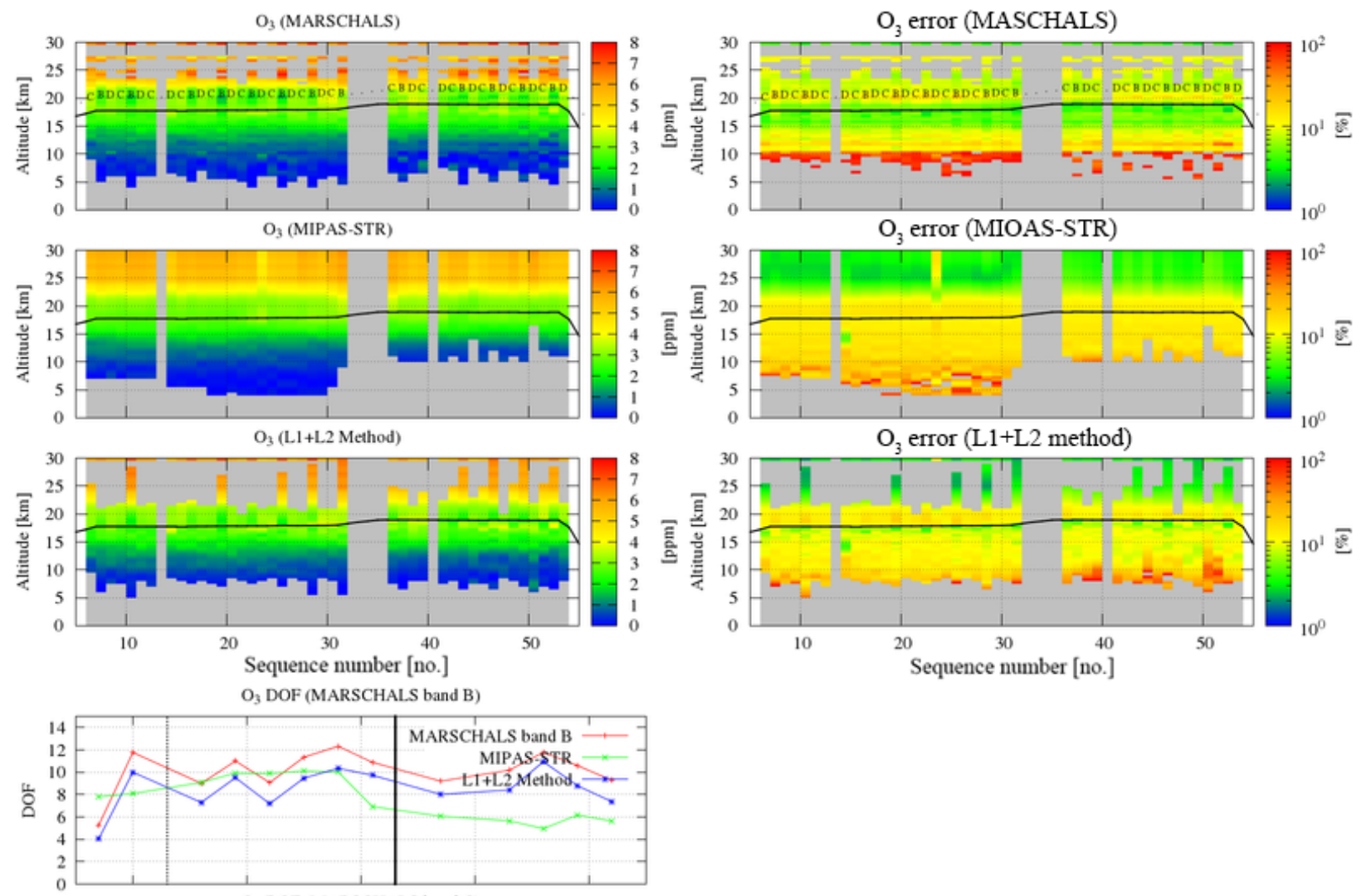

$\mathrm{O}_{3}$ DOF (MARSCHALS band C)
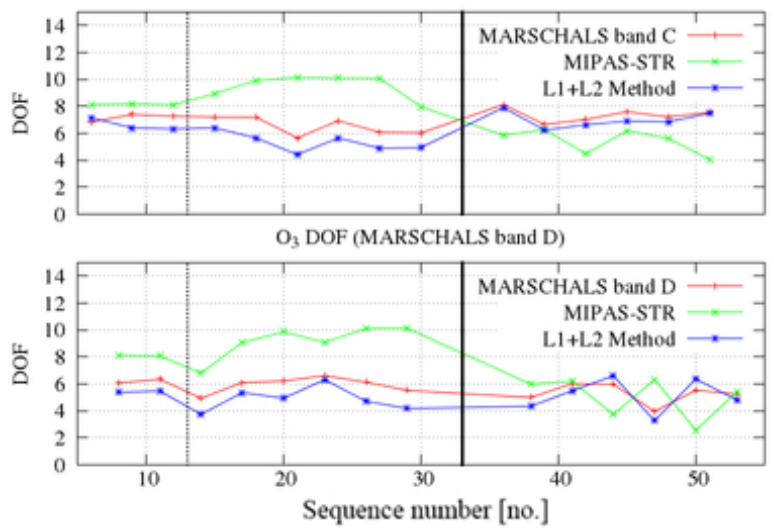

Figure 10. $\mathrm{O}_{3}$ retrieved results obtained from initial analyses and (L1 + L2) data fusion of MARSCHALS and MIPAS-STR limb sounding observations: vertical profiles (top left panel), total relative error profiles (top right panel) and number of DOF (bottom panel).

The RID (relative information distribution) is independent from the chosen retrieval approaches and from the external constraint so it is not reported in Fig. 10 and it is not discussed any further in this section. The SF (synergy factor) can also be evaluated for the (L1 + L2) approach. However, the results obtained are quite inconsistent with the ones of the MSS method. For example, $\mathrm{O}_{3} \mathrm{SF}$ is 1 in the altitude range between 10 and $20 \mathrm{~km}$, where the MSS showed the maximum of the synergy, and similar behavior is observed in the case of the other targets (Fig. 11). This is due to the different retrieval approach and different external constraints used for
MARSCHALS and MIPAS-STR data analysis, which produce retrieval errors that are not directly comparable. The SF is a quantitative comparison of the errors of the individual analyses with respect to the data fusion analysis and for this reason, the SF can not be significant in this case.

Contrariwise, the improvement brought by data synergy of individual measurements is evident when using the MSS approach, which is capable of evaluating the contribution of measurement space component with no impact of different external constraints, and the results can be represented with the same constraints a posteriori applied both to the 

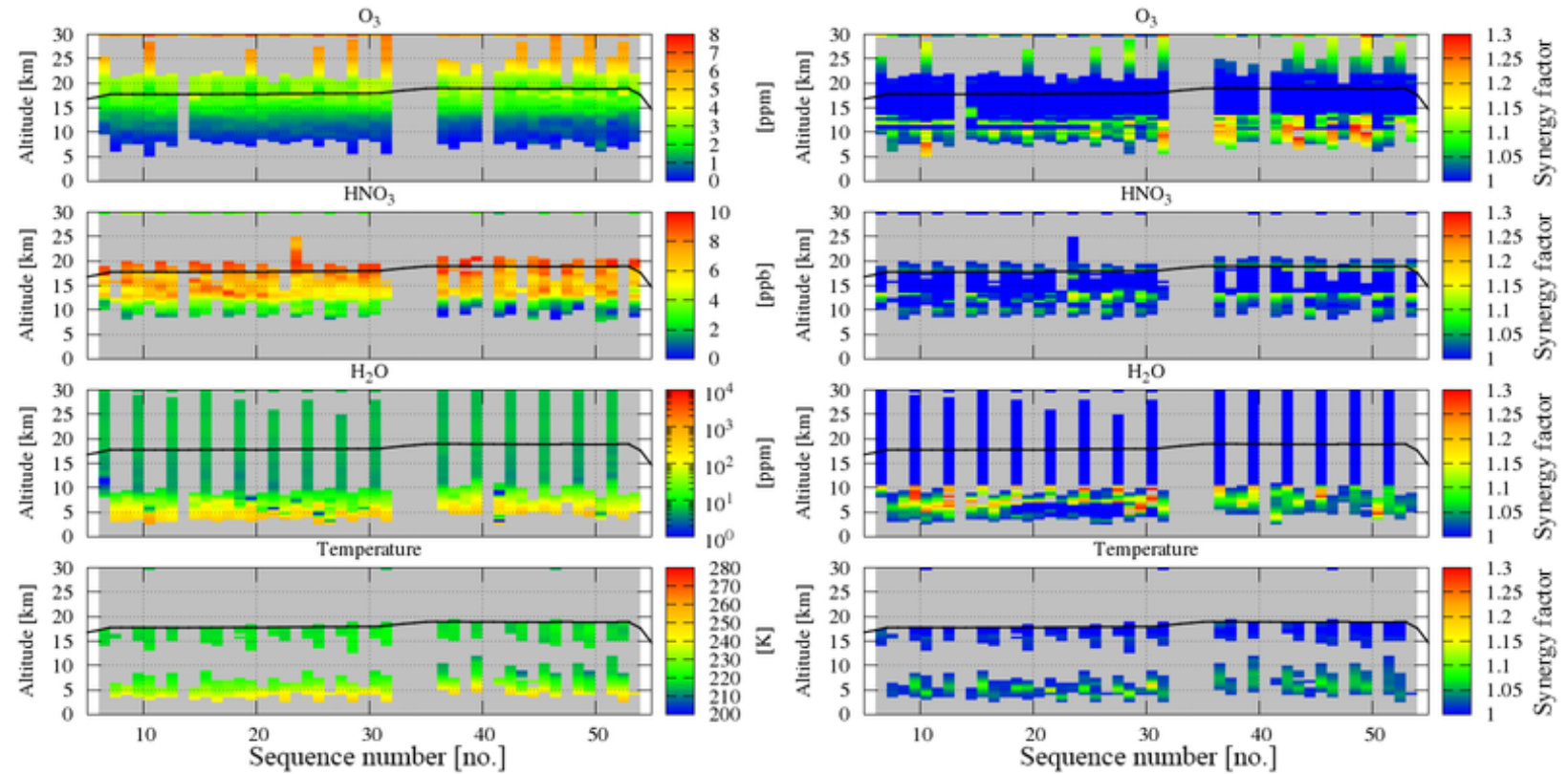

Figure 11. (L1 + L2) method products and SF for the atmospheric targets as resulting from initial retrievals and (L1 + L2) method of MARSCHALS and MIPAS-STR limb sounding observations.

individual and the combined measurements. We notice that the profiles and errors of the initial MIPAS-STR data product used for the $(\mathrm{L} 1+\mathrm{L} 2)$ method have to be seen in the context of the smoothing inherent to the utilized constraint. The altitude-dependent degree of smoothing of the MIPASSTR data product is not included into the $(\mathrm{L} 1+\mathrm{L} 2)$ method. Therefore, too strong a constraint is imposed in OE processing of the MARSCHALS observations using the MIPASSTR data as a priori at altitudes where the MIPAS-STR results include low information. Consequently, the additional information provided by MARSCHALS cannot be exploited sufficiently under such conditions. In contrast, MSS calculations allow the separation of the measurement components from their associated a priori information, and the result of the data fusion can be represented using the same external constraint. This facilitates the comparative evaluation of the total uncertainty associated with individual and synergistic retrieval products.

We come to the conclusion that the application of the (L1 + L2) method using different retrieval methods for the $\mathrm{mm}$-waves and IR measurements qualitatively demonstrates the synergy between the different techniques; but quantitative comparisons are difficult since the characteristics of the different retrieval methods are not fully compatible.

An improved quantitative comparability might be obtained by using the same retrieval method, constraint and a priori knowledge for both techniques and optimizing the retrievals for the same key aspects.

In contrast, the MSS method allows for a clearer comparison of the individual results and the results of the data syn- ergy, since the measured components from the different techniques are treated in a similar way and the results are subject to the same external constraint.

\section{Conclusions}

We have presented a dedicated and thorough study investigating the quality of synergistic data products obtained from the combination of middle infrared and mm-wave limb sounding measurements of trace gases and temperature profile in the UTLS compared to that of the individual retrieval products. The calculation of synergistic profiles of the targets was performed using a posteriori combination of individual L2 data rather than simultaneous inversion of L1 data. We have studied the performance of the innovative method of MSS (Measurement Space Solution) data fusion with respect to the standard approach of $(\mathrm{L} 1+\mathrm{L} 2)$ method. A quantitative estimate of the results was achieved based on a specific set of quantifiers including the total retrieval error, the number of DOFs, the RID and the SF. The conclusions drawn in this paper are based on the outcome of the analysis of measurements acquired by the MIPAS-STR and MARSCHALS instruments on-board the M-55 Geophysica aircraft during the flight on 10 March 2010 from Kiruna, Sweden, for the study of the Arctic UTLS in the framework of the PremierEx scientific campaign, which offered favorable atmospheric conditions for the investigation of the complementary capabilities of middle infrared and $\mathrm{mm}$-wave limb sounding observations in clear and cloudy sky. 
The MSS data fusion method was successfully applied to the analysis of all the atmospheric targets considered in the study, i.e., $\mathrm{O}_{3}, \mathrm{HNO}_{3}, \mathrm{H}_{2} \mathrm{O}$ and temperature, to quantitatively assess the improvement in remote sounding capabilities of the UTLS.

In general, the fused products overcome the individual limitations of the middle infrared and millimeter-wave measurements due, respectively, to the presence of low- and highaltitude clouds in leg 1 and leg 3 of the flight and to water vapor absorption in the upper troposphere, especially in the clear sky conditions of leg 2 , resulting in a more stable pattern of performance throughout the flight.

The redundant and complementary information content of middle infrared and $\mathrm{mm}$-wave measurements in the limb geometry are effectively exploited by the MSS data fusion approach in the case of $\mathrm{O}_{3}$ profiling, as demonstrated by the increase - from 0.8 to 4.5 - of the number of DOF of fused data compared to individual products. The major impact (i.e., SF values around 1.2 at altitudes between 25 and $15 \mathrm{~km}$ ) results from the combination of MIPAS-STR data and the measurements of MARSCHALS band C and D with less sensitivity to $\mathrm{O}_{3}$ concentration. A reverse situation occurs with $\mathrm{HNO}_{3}$, for which MARSCHALS band B is less sensitive compared to band $\mathrm{C}$ and $\mathrm{D}$ and much better performance is obtained in the middle infrared with respect to the mm-waves, once again only limited by the presence of clouds. The synergistic effects, reaching a maximum SF of 1.2 in leg 3 of the flight for band D between 10 and $20 \mathrm{~km}$, are exploited to achieve better performance over an extended altitude range.

The results of MSS data fusion for $\mathrm{H}_{2} \mathrm{O}$ demonstrate significant improvement with respect to the individual retrieval products, both when combining MIPAS-STR observations and MARSCHALS limb scans in band $\mathrm{C}$, as well as in the case of band $\mathrm{B}$ and $\mathrm{D}$ (having a weaker signal-to-noise ratio for $\mathrm{H}_{2} \mathrm{O}$ compared to band $\mathrm{C}$ ), as evident from total uncertainties, DOF and RID values. The highest values of the SF are found for band $\mathrm{B}$ and band $\mathrm{D}$ in the first two legs of the flight (with max. up to 1.3), while in the presence of high clouds at leg 3, SF is always less than 1.1.

The combination of temperature data from MIPAS-STR and MARSCHALS measurements increases the number of DOF of 0.8 in clear sky conditions and from 1.1 (leg 1) to 1.9 (leg 3) in cloudy sky, while RID (relative information distribution) values show the effect of complementary strengths of middle infrared and mm-wave sounding, in particular in compensating for the lack of MIPAS-STR measurements below $10 \mathrm{~km}$ in leg 3 . The latter effect provides evidence of the improvement in the quality of the target products obtained by the MSS data fusion where only one of the two instruments acquired useful measurements. The same mechanism was observed, even if to a weaker degree compared to temperature, in the fusion of the $\mathrm{H}_{2} \mathrm{O}$ profiles.

The comparison of the MSS method with the fusion of $\mathrm{O}_{3}$ VMR profiles using the $(\mathrm{L} 1+\mathrm{L} 2)$ method allowed us to further highlight the effectiveness of the first innovative ap- proach with respect to a standard and consolidated procedure for the combination of two or more individual measurements.

The number of DOFs of the fused $\mathrm{O}_{3}$ profiles obtained from application of the (L1 + L2) method shows the limits of the implemented approach for combining the information independently acquired by MIPAS-STR and MARSCHALS measurements. These limits result from the assumption that the L2 products from MIPAS-STR inversion have an AK matrix equal to the identity matrix. By using MIPASSTR retrieved profiles, as a priori for the inversion of MARSCHALS limb radiances, we neglect the effects of smoothing that must be taken into account to apply the $(\mathrm{L} 1+\mathrm{L} 2)$ method properly. The SF, on the other hand, also provides inconsistent results for the $(\mathrm{L} 1+\mathrm{L} 2)$ method with respect to the MSS method, showing no synergy (SF equal to 1) where the SF values of the MSS products for $\mathrm{O}_{3}$ are largest. The inconsistencies observed in the $(\mathrm{L} 1+\mathrm{L} 2)$ results emerge basically from the fact that different retrieval strategies are applied to inversion of MIPAS-STR and MARSCHALS limb radiances. As a consequence, the total uncertainties associated with the individual retrieval products cannot be directly compared and the altitude-dependent degree of smoothing adopted in MIPAS-STR analysis provides a strong a priori for the inversion of MARSCHALS spectra at altitudes where the information of middle infrared measurements is low. We conclude that a quantitative assessment of synergistic effects due to the combination of middle infrared and mm-wave limb sounding can be achieved by using the MSS data fusion method, but is generally not possible in the case of the (L1 + L2) approach.

In our study, we have demonstrated for the first time that for the representation of the vertical profiles resulting from the MSS data fusion, we can apply the Tikhonov-Phillips regularization. In the present paper, we described the procedure developed to implement this option as an alternative to the method based on the use of a weighted mean between the profiles obtained from the MSSs and a climatological profile in full detail.

As a further lesson learned from the study we might also consider the series of open issues that our activity has identified and that deserve further investigation because of their potential impact on the retrieval of the state of the atmosphere from indirect measurements by multiple sources.

Among these issues, it is relevant to mention that our choice of applying Tikhonov Phillips regularization for the representation of the fused profiles calculated using the MSS method was mostly due to the aim to test this option for the first time for the fusion of real data. The discussion on requirements and constraints for optimal determination of the null-space component (e.g., the approach of OE, based on the use of an absolute a priori profile in alternative to TikhonovPhillips regularization, using the first derivative of an a priori) is beyond the scope of this paper. Similarly, we must notice here that the limitations and drawbacks encountered in our application of the (L1 + L2) method of data fusion could 
be mitigated by considering the effect of smoothing, which we have not taken into account in the results reported in this paper. As demonstrated by Ceccherini et al. (2014), this can be done by applying the generalized inversion, whose outcome we plan to compare with the results of the MSS data fusion in the next steps of our study.

Finally, the distinction we made in the introduction between data fusion methods aimed at combining the information content from independent measurements and assimilation schemes, which perform model data fusion, is the necessary premise to further investigate the exploration of the potential of assimilation of fused products. This is precisely the focus of a 3-year study which some of the authors will be carrying out for the AURORA (Advanced Ultraviolet Radiation and Ozone Retrieval for Applications) project granted by the European Commission in the framework of the Horizon 2020 program (Call H2020-EO-2015 Earth Observation; topic EO-2-2015: Stimulating wider research use of Copernicus Sentinel Data) using simulated measurements of the Sentinel 4 and Sentinel 5 missions.

Acknowledgements. The research activities presented in this paper were conducted under ESA contract no. 4000101374/10/NL/CT, in the framework of the project PREMIER Analysis of Campaign Data and subsequent extension. We thank Myasishchev Design Bureau and the Geophysica team for a successful aircraft campaign. We thank the instrument teams of MARSCHALS and MIPAS-STR for their work which made this study possible. We also wish to express our gratitude to Bruno Carli (IFAC-CNR) for his valuable suggestions and comments.

Edited by: J. Worden

\section{References}

Aires, F.: Measure and exploitation of multisensor and multiwavelength synergy for remote sensing: 1 . Theoretical considerations, J. Geophys. Res., 116, D02301, doi:10.1029/2010JD014701, 2011.

Aires, F., Aznay, O., Prigent, C., Paul, M., and Bernardo, F.: Synergistic multi-wavelength remote sensing versus a posteriori combination of retrieved products: application for the retrieval of atmospheric profiles using MetOp-A, J. Geophys. Res., 117, D18304, doi:10.1029/2011JD017188, 2012.

Aschbacher, J. and Milagro-Pérez, M. P.: The European Earth monitoring (GMES) programme: status and perspectives, Remote Sens. Environ., 120, 3-8, doi:10.1016/j.rse.2011.05.028, 2012.

Bianchini, G., Carli, B., Cortesi, U., Del Bianco, S., Gai, M., and Palchetti, L.: Test of far-infrared atmospheric spectroscopy using wide-band balloon-borne measurements of the upwelling radiance, J. Quant. Spectrosc. Ra., 109, 1030-1042, 2008.

Carli, B., Bazzini, G., Castelli, E., Cecchi-Pestellini, C., Del Bianco, S., Dinelli, B. M., Gai, M., Magnani, L., Ridolfi, M., and Santurri, L.: MARC: a code for the retrieval of atmospheric parameters from millimeter-wave limb measurements, J. Quant. Spectrosc. Ra., 105, 476-491, 2007.
Carlotti, M.: Global-fit approach to the analysis of limb-scanning atmospheric measurements, Appl. Optics, 27, 3250-3254, 1988.

Castelli, E., M. Dinelli, B., Del Bianco, S., Gerber, D., Moyna, B. P., Siddans, R., Kerridge, B. J., and Cortesi, U.: Measurement of the Arctic UTLS composition in presence of clouds using millimetre-wave heterodyne spectroscopy, Atmos. Meas. Tech., 6, 2683-2701, doi:10.5194/amt-6-2683-2013, 2013.

Castelli, E., Del Bianco, S., Dinelli, B. M., Gerber, D., Oelhaf, H., Woiwode, W., Vogel, B., Sinnhuber, B.-M., Ruhnke, R., and Cortesi, U.: Results of the preparatory study "PREMIER Analysis of Campaign Data”, Ann. Geophys.-Italy, 56, 1-10, 2014.

Ceccherini, S., Raspollini, P., and Carli, B.: Optimal use of the information provided by indirect measurements of atmospheric vertical profiles, Opt. Express, 17, 4944-4958, 2009.

Ceccherini, S., Carli, B., Cortesi, U., Del Bianco, S., and Raspollini, P.: Retrieval of the vertical column of an atmospheric constituent from data fusion of remote sensing measurements, J. Quant. Spectrosc. Ra., 111, 507-514, 2010a.

Ceccherini, S., Cortesi, U., Del Bianco, S., Raspollini, P., and Carli, B.: IASI-METOP and MIPAS-ENVISAT data fusion, Atmos. Chem. Phys., 10, 4689-4698, doi:10.5194/acp-10-4689-2010, 2010b.

Ceccherini, S., Carli, B., and Raspollini, P.: Quality quantifier of indirect measurements, Opt. Express, 20, 5151-5167, 2012.

Ceccherini, S., Carli, B., and Raspollini, P.: Quality of MIPAS operational products, J. Quant. Spectrosc. Ra., 121, 45-55, 2013.

Ceccherini, S., Carli, B., and Raspollini, P.: The average of atmospheric vertical profiles, Opt. Express, 22, 24808-24816, 2014.

Cortesi, U., Del Bianco, S., Gai, M., Dinelli, B. M., Castelli, E., Gerber, D., Oelhaf, H., Woiwode, W., PREMIER Analysis of Campaign Data, ESA-ESTEC Contract 4000101374/NL/10/CT, Special Issue, TSRR IFAC-CNR, available at: http://www.ifac. cnr.it/images/stories/libri/archivio/VOL4/3-12.pdf (last access: 5 October 2015), 2012.

Dinelli, B. M., Alpaslan, D., Carlotti, M., Magnani, L., and Ridolfi, M.: Multi-target retrieval (MTR): the simultaneous retrieval of pressure, temperature and volume mixing ratio profiles from limb-scanning atmospheric measurements, J. Quant. Spectrosc. Ra., 84, 141-157, 2004.

Dinelli, B. M., Baronti, S., Bazzini, G., Blom, C., Carli, B., Castelli, E., Ceccherini, S., Cecchi Pestellini, C., Chipperfield, M., Cortesi, U., Del Bianco, S., Dudhia, A., Flaud, J. M., Gai, M., Magnani, L., Piccolo, C., Raspollini, P., Ridolfi, M., Santurri, L., and Urban, J.: The Scientific Analysis of Limb Sounding Observations of the Upper Troposphere, Final Report of ESA ESTEC/Contract 16530/02/NL/MM, IFAC-CNR, Sesto Fiorentino, Italia, 2007.

Dinelli, B. M., Castelli, E., Carli, B., Del Bianco, S., Gai, M., Santurri, L., Moyna, B. P., Oldfield, M., Siddans, R., Gerber, D., Reburn, W. J., Kerridge, B. J., and Keim, C.: Technical Note: Measurement of the tropical UTLS composition in presence of clouds using millimeter-wave heterodyne spectroscopy, Atmos. Chem. Phys., 9, 1191-1207, doi:10.5194/acp-9-1191-2009, 2009.

ESA: Report for Mission Selection: PREMIER, ESA SP-1324/3, European Space Agency, Noordwijk, the Netherlands, 2012.

Fischer, H., Birk, M., Blom, C., Carli, B., Carlotti, M., von Clarmann, T., Delbouille, L., Dudhia, A., Ehhalt, D., Endemann, M., Flaud, J. M., Gessner, R., Kleinert, A., Koopman, R., Langen, J., López-Puertas, M., Mosner, P., Nett, H., Oelhaf, H., Perron, G., 
Remedios, J., Ridolfi, M., Stiller, G., and Zander, R.: MIPAS: an instrument for atmospheric and climate research, Atmos. Chem. Phys., 8, 2151-2188, doi:10.5194/acp-8-2151-2008, 2008.

Fisher, R. A.: The logic of inductive inference, J. R. Stat. Soc., 98, 39-54, 1935.

Friedl-Vallon, F., Gulde, T., Hase, F., Kleinert, A., Kulessa, T., Maucher, G., Neubert, T., Olschewski, F., Piesch, C., Preusse, P., Rongen, H., Sartorius, C., Schneider, H., Schönfeld, A., Tan, V., Bayer, N., Blank, J., Dapp, R., Ebersoldt, A., Fischer, H., Graf, F., Guggenmoser, T., Höpfner, M., Kaufmann, M., Kretschmer, E., Latzko, T., Nordmeyer, H., Oelhaf, H., Orphal, J., Riese, M., Schardt, G., Schillings, J., Sha, M. K., Suminska-Ebersoldt, O., and Ungermann, J.: Instrument concept of the imaging Fourier transform spectrometer GLORIA, Atmos. Meas. Tech., 7, 35653577, doi:10.5194/amt-7-3565-2014, 2014.

Höpfner, M., Blom, C. E., Echle, G., Glatthor, N., Hase, F., and Stiller, G.: Retrieval simulations for MIPAS-STR measurements, in: IRS 2000: Current Problems in Atmospheric Radiation, edited by: Smith, W. L., Proc. of the Internat. Radiation Symp., St. Petersburg, Russia, 24-29 July 2000 Hampton, Va., DEEPAK Publ., 2001.

Ingmann, P., Veihelmann, B., Langen, J., Lamarre, D., Stark, H., and Bazalgette Courréges-Lacoste, G.: Requirements for the GMES Atmosphere Service and ESA's implementation concept: Sentinels-4/-5 and -5p, Remote Sens. Environ., 120, 58-69, 2012.

Keim, C., Liu, G. Y., Blom, C. E., Fischer, H., Gulde, T., Höpfner, M., Piesch, C., Ravegnani, F., Roiger, A., Schlager, H., and Sitnikov, N.: Vertical profile of peroxyacetyl nitrate (PAN) from MIPAS-STR measurements over Brazil in February 2005 and its contribution to tropical UT NOy partitioning, Atmos. Chem. Phys., 8, 4891-4902, doi:10.5194/acp-8-4891-2008, 2008.

Lahoz, W., Khattatov, B., and Menard, R. (Eds.): Data Assimilation: Making Sense of Observations, Springer Science and Business Media, Berlin, Germany, 2010.

Lossow, S., Steinwagner, J., Urban, J., Dupuy, E., Boone, C. D., Kellmann, S., Linden, A., Kiefer, M., Grabowski, U., Glatthor, N., Höpfner, M., Röckmann, T., Murtagh, D. P., Walker, K. A., Bernath, P. F., von Clarmann, T., and Stiller, G. P.: Comparison of HDO measurements from Envisat/MIPAS with observations by Odin/SMR and SCISAT/ACE-FTS, Atmos. Meas. Tech., 4, 1855-1874, doi:10.5194/amt-4-1855-2011, 2011.

McMillin, L., Fleming, H., Gray, D., Grody, N., Reale, A., Hayden, C. M., Smith, W. L., and Susskind, J.: The Complementary Roles of Microwave and Infrared Instruments in Atmospheric Sounding, NOAA Technical Report, NASA STI Program STI Support Services, Hampton, VA, USA, 1987.

Moyna, B., Oldfield, M., Gerber, D., Rea, S., Siddans, R., and Kerridge, B.: Technical Report: UAMS Upgrades of MARSCHALS - Technical Data Pack, Final Report of ESA Contract 21990/08/NL/EL, European Space Agency, Noordwijk, the Netherlands, 2010.

Oldfield, M., Moyna, B. P., Allouis, E., Brunt, R., Cortesi, U., Brian, N., Ellison, N., Eskell, J., Forward, T., Jones, T., Lamarre, D., Langen, J., de Maagt, P. J. I., Matheson, D. N., Morgan, I., Reburn, J., and Siddans, R.: MARSCHALS: development of an airborne millimeter-wave limb sounder, Proc. SPIE 4540, Sensors, Systems, and Next-Generation Satellites V, 221, 2001.
Phillips, C.: A technique for the numerical solution of certain integral equations of the first kind, J. ACM, 9, 84-97, 1962.

Piesch, C., Gulde, T., Sartorius, C., Friedl-Vallon, F., Seefeldner, M., Wölfel, M., Blom, C. E., and Fischer, H.: Design of a MIPAS Instrument for High-Altitude Aircraft, Proc. of the 2nd Internat. Airborne Remote Sensing Conference and Exhibition, ERIM, Ann Arbor, MI, Vol. II, 199-208, 24-27 June 1996, San Francisco, 1996.

Remedios, J. J., Leigh, R. J., Waterfall, A. M., Moore, D. P., Sembhi, H., Parkes, I., Greenhough, J., Chipperfield, M.P., and Hauglustaine, D.: MIPAS reference atmospheres and comparisons to V4.61/V4.62 MIPAS level 2 geophysical data sets, Atmos. Chem. Phys. Discuss., 7, 9973-10017, doi:10.5194/acpd-79973-2007, 2007.

Riese, M., Oelhaf, H., Preusse, P., Blank, J., Ern, M., FriedlVallon, F., Fischer, H., Guggenmoser, T., Höpfner, M., Hoor, P., Kaufmann, M., Orphal, J., Plöger, F., Spang, R., SuminskaEbersoldt, O., Ungermann, J., Vogel, B., and Woiwode, W.: Gimballed Limb Observer for Radiance Imaging of the Atmosphere (GLORIA) scientific objectives, Atmos. Meas. Tech., 7, 19151928, doi:10.5194/amt-7-1915-2014, 2014.

Rodgers, C.: Inverse Methods for Atmospheric Sounding: Theory and Practice. Vol. 2 of Series on Atmospheric, Oceanic and Planetary Physics, Singapore, World Scientific, 2000.

Smith Sr., W. L., Revercomb, H., Bingham, G., Larar, A., Huang, H., Zhou, D., Li, J., Liu, X., and Kireev, S.: Technical Note: Evolution, current capabilities, and future advance in satellite nadir viewing ultra-spectral IR sounding of the lower atmosphere, Atmos. Chem. Phys., 9, 5563-5574, doi:10.5194/acp-95563-2009, 2009.

Spang, R., Remedios, J. J., and Barkley, M. P.: Colour indices for the detection and differentiation of cloud types in infra-red limb emission spectra, Adv. Space Res., 33, 1041-1047, 2004.

Staelin, D. H., and Kerekes, J. P.: Combined microwave and optical atmospheric remote sensing techniques: a review, Combined Optical-Microwave Earth and Atmosphere Sensing, Second Topical Symposium on IEEE, 3-6 April 1995, Atlanta, GA, USA, 1995.

Stiller, G. P., von Clarmann, T., Funke, B., Glatthor, N., Hase, F., Höpfner, M., and Linden, A.: Sensitivity of trace gas abundances retrievals from infrared limb emission spectra to simplifying approximations in radiative transfer modelling, J. Quant. Spectrosc. Ra., 72, 249-280, 2002.

Tikhonov, A.: On the solution of incorrectly stated problems and a method of regularization, Dokl. Akad. Nauk SSSR+, 151, 501504, 1963.

Ungermann, J., Kalicinsky, C., Olschewski, F., Knieling, P., Hoffmann, L., Blank, J., Woiwode, W., Oelhaf, H., Hösen, E., Volk, C. M., Ulanovsky, A., Ravegnani, F., Weigel, K., Stroh, F., and Riese, M.: CRISTA-NF measurements with unprecedented vertical resolution during the RECONCILE aircraft campaign, Atmos. Meas. Tech., 5, 1173-1191, doi:10.5194/amt-5-11732012, 2012.

von Hobe, M., Bekki, S., Borrmann, S., Cairo, F., D’Amato, F., Di Donfrancesco, G., Dörnbrack, A., Ebersoldt, A., Ebert, M., Emde, C., Engel, I., Ern, M., Frey, W., Genco, S., Griessbach, S., Grooß, J.-U., Gulde, T., Günther, G., Hösen, E., Hoffmann, L., Homonnai, V., Hoyle, C. R., Isaksen, I. S. A., Jackson, D. R., Jánosi, I. M., Jones, R. L., Kandler, K., Kalicinsky, C., 
Keil, A., Khaykin, S. M., Khosrawi, F., Kivi, R., Kuttippurath, J., Laube, J. C., Lefèvre, F., Lehmann, R., Ludmann, S., Luo, B. P., Marchand, M., Meyer, J., Mitev, V., Molleker, S., Müller, R., Oelhaf, H., Olschewski, F., Orsolini, Y., Peter, T., Pfeilsticker, K., Piesch, C., Pitts, M. C., Poole, L. R., Pope, F. D., Ravegnani, F., Rex, M., Riese, M., Röckmann, T., Rognerud, B., Roiger, A., Rolf, C., Santee, M. L., Scheibe, M., Schiller, C., Schlager, H., Siciliani de Cumis, M., Sitnikov, N., Søvde, O. A., Spang, R., Spelten, N., Stordal, F., Sumińska-Ebersoldt, O., Ulanovski, A., Ungermann, J., Viciani, S., Volk, C. M., vom Scheidt, M., von der Gathen, P., Walker, K., Wegner, T., Weigel, R., Weinbruch, S., Wetzel, G., Wienhold, F. G., Wohltmann, I., Woiwode, W., Young, I. A. K., Yushkov, V., Zobrist, B., and Stroh, F.: Reconciliation of essential process parameters for an enhanced predictability of Arctic stratospheric ozone loss and its climate interactions (RECONCILE): activities and results, Atmos. Chem. Phys., 13, 9233-9268, doi:10.5194/acp-13-9233-2013, 2013.
Woiwode, W., Oelhaf, H., Gulde, T., Piesch, C., Maucher, G., Ebersoldt, A., Keim, C., Höpfner, M., Khaykin, S., Ravegnani, F., Ulanovsky, A. E., Volk, C. M., Hösen, E., Dörnbrack, A., Ungermann, J., Kalicinsky, C., and Orphal, J.: MIPAS-STR measurements in the Arctic UTLS in winter/spring 2010: instrument characterization, retrieval and validation, Atmos. Meas. Tech., 5, 1205-1228, doi:10.5194/amt-5-1205-2012, 2012.

Woiwode, W., Sumińska-Ebersoldt, O., Oelhaf, H., Höpfner, M., Belyaev, G. V., Ebersoldt, A., Friedl-Vallon, F., Grooß, J.-U., Gulde, T., Kaufmann, M., Kleinert, A., Krämer, M., Kretschmer, E., Kulessa, T., Maucher, G., Neubert, T., Piesch, C., Preusse, P., Riese, M., Rongen, H., Sartorius, C., Schardt, G., Schönfeld, A., Schuettemeyer, D., Sha, M. K., Stroh, F., Ungermann, J., Volk, C. M., and Orphal, J.: Validation of first chemistry mode retrieval results from the new limb-imaging FTS GLORIA with correlative MIPAS-STR observations, Atmos. Meas. Tech., 8, 2509-2520, doi:10.5194/amt-8-2509-2015, 2015. 